\title{
Molecular Characterization and Defense Functions of the Nile Tilapia (Oreochromis niloticus) DnaJ B9b and DnaJ C3a Genes in Response to Pathogenic Bacteria under High-Temperature Stress Conditions
}

\author{
Prapansak Srisapoome ${ }^{1,2,3, * \mathbb{C}}$, Kubpaphas Thummabancha ${ }^{1,2,3}$ and Ratree Wongpanya ${ }^{4}$ \\ 1 Laboratory of Aquatic Animal Health Management, Department of Aquaculture, Faculty of Fisheries, \\ Kasetsart University, Chatuchak, Bangkok 10900, Thailand; t.kubpaphas@gmail.com \\ 2 Center of Advanced Studies for Agriculture and Food, Kasetsart University Institute for Advanced Studies, \\ Kasetsart University, Bangkok 10900, Thailand \\ 3 Center of Excellence in Aquatic Animal Health Management, Faculty of Fisheries, Kasetsart University, \\ Chatuchak, Bangkok 10900, Thailand \\ 4 Department of Biochemistry, Faculty of Science, Kasetsart University, Bangkok 10900, Thailand; \\ fscirtw@ku.ac.th \\ * Correspondence: ffispssp@ku.ac.th; Tel.: +66-2579-2924
}

\section{check for}

updates

Citation: Srisapoome, P.; Thummabancha, K.; Wongpanya, R. Molecular Characterization and Defense Functions of the Nile Tilapia (Oreochromis niloticus) DnaJ B9b and DnaJ C3a Genes in Response to Pathogenic Bacteria under High-Temperature Stress Conditions. Biomolecules 2021, 11, 1509. https:// doi.org/10.3390/biom11101509

Academic Editor: Hidetaka Torigoe

Received: 25 August 2021

Accepted: 10 October 2021

Published: 13 October 202

Publisher's Note: MDPI stays neutral with regard to jurisdictional claims in published maps and institutional affiliations.

Copyright: (c) 2021 by the authors. Licensee MDPI, Basel, Switzerland. This article is an open access article distributed under the terms and conditions of the Creative Commons Attribution (CC BY) license (https:/ / creativecommons.org/licenses/by/ $4.0 /$ )

\begin{abstract}
DnaJ proteins or heat shock protein 40s (HSP40s) form one of the largest heat shock protein families. In this study, 2 cDNAs encoding Nile tilapia (Oreochromis niloticus) DnaJ proteins (On-DnaJ $\mathrm{B} 9 \mathrm{~b}$ and On-DnaJ C3a) were successfully cloned and characterized. The structures and organizations of these two genes are first reported in the present study. On-DnaJ B9b is approximately $2.1 \mathrm{~kb}$ long and contains 2 exons and 1 intron, while $\mathrm{On}$-DnaJ $\mathrm{C} 3 a$ is approximately $12 \mathrm{~kb}$ long and contains 12 exons and 11 introns. Under normal conditions, On-DnaJ B9b mRNA is highly expressed in gonad and trunk kidney tissues, while $\mathrm{On}$-DnaJ $\mathrm{C} 3 a$ transcripts are abundantly expressed in gills, intestine, liver, and trunk kidney tissues. Following pathogenic infections, the expression of both genes is induced in the liver, spleen and head kidney tissues of Nile tilapia that were infected with two virulent pathogenic bacteria, Streptococcus agalactiae and Flavobacterium columnare. Silencing of these two genes was first carried out, and the results clearly indicated their crucial roles under both heat and bacterial stress conditions. The fundamental knowledge obtained from this study indicates the characteristic basic biofunctions of heat shock proteins in the regulation of intracellular proteins during infection, which involve preventing protein aggregation, promoting protein refolding, and activating unfolded protein degradation.
\end{abstract}

Keywords: molecular chaperone; heat shock protein; Hsp40; aquaculture; Streptococcosis; columnaris; RNAi

\section{Introduction}

Nile tilapia (Oreochromis niloticus) is a tropical teleost fish that is cultured worldwide because of its substantial economic and trade value and its high annual production rate [1]. Since it is classified as a fast-growing, eurythermal and euryhaline aquatic animal, it was introduced for cultivation in many areas around the world [1]. As such, its culture has increased and become extensive. However, poor management of this culture or rapid changes in water quality have resulted in the presence of undesirable pathogenic microorganisms, which can negatively affect the health of these fish, leading to their death and the loss of their economic trade value [2]. An increase in high temperature $\left(>31^{\circ} \mathrm{C}\right)$ or rapid fluctuation in this factor were observed to induce high susceptibility to some bacterial diseases, such as streptococcosis and columnaris [3]

Streptococcosis is a common infectious bacterial disease of tilapia worldwide caused by Streptococcus spp. The most common species that usually causes streptococcosis out- 
breaks is Streptococcus agalactiae. This bacterium is gram-positive and exhibits a spherical shape, a red blood cell lysing capability, lactic acid production during the fermentative process and catalase negativity [3]. Diseased fish display septicemia and severe meningoencephalitis [4]. Generally, infected fish exhibit skin hemorrhage, exophthalmia, ascites, uncontrollable swimming and anorexia [5].

Columnaris disease is a bacterial infection that has a high mortality rate in warm-water fish [6]. This disease is characterized by gill necrosis, grayish-white patches on the body, skin erosion, and fin rot [7]. The main causative agent of this disease is Flavobacterium columnare, which is a gram-negative bacterium with a long rod shape and gliding motility [8]. F. columnare is a fastidious microorganism that needs to be grown in specific media, such as Shieh's selective medium [9]. The rapid expansion of these diseases throughout tilapia farms has become a major concern to researchers who are working to improve prophylactic strategies.

Many scientific papers have reported that during infection and inflammatory states, various heat shock proteins (HSPs) show significantly upregulated expression compared with those under normal conditions [10-14]. Generally, HSPs can be classified into many subclasses depending on their molecular weights [11]. The main functions of HSPs involve the folding of native proteins, the refolding of denatured proteins, the degrading of misfolded proteins and acting as secondary signal messengers in cells [15]. HSPs are widely distributed throughout cellular compartments including the nucleus, cytoplasm, endoplasmic reticulum (ER) and Golgi apparatus [16]. HSPs also play a major role in intracellular antigenic processing in antigen presenting cells (APCs) through major histocompatibility complex (MHC) class I [10,17].

Recently, an increasing number of relevant studies have established a correlation between ER stress and infections [18-20]. The unfolded protein response (UPR) is a cellular stress process that occurs in the ER lumen [21]. DnaJ (HSP40), ER DnaJ (ERdj) homolog and microvascular differentiation gene $1(M d g 1)$ are a group of cellular proteins located in the ER lumen and are rapidly expressed in response to UPR induction to regulate and maintain proper folding of denatured proteins in the lumen [22,23]. Under cellular stress conditions, DnaJ proteins trap unfolded/misfolded proteins. These molecules carry impaired proteins to bind immunoglobulin protein (BiP) or $78 \mathrm{kDa}$ glucose-regulated protein (GRP78), which is strictly located in the ER lumen and belong to the HSP70 family [24,25]. BiP later initiates binding and refolds client proteins into their correct structure so that they can function properly. Recently, the DnaJ B9b and DnaJ C3a proteins were found to be induced during ER stress $[25,26]$. DnaJ B9b is involved in the ER-associated degradation (ERAD) pathway; it plays a major role in the degradation of ERAD substrates by sending clients through the integral membrane protein Derlin-1, which is an ERAD component, to promote proteasomal degradation [25-27]. DnaJ C3a binds to unfolded substrates via its tetratricopeptide repeat (TPR) motif, which maintains protein folding homeostasis and promotes protein refolding in the ER lumen under UPR activation $[25,28,29]$.

The complementary DNAs (cDNAs) that encode the DnaJ proteins important for UPR and ER stress responses, the structures of the encoding genes, and the biological defense functions of these proteins in Nile tilapia have not been characterized. Therefore, this study was conducted to better define the chaperone requirements and elucidate the crucial biological functions of DnaJ B9b and DnaJ C3a under various conditions in the target organism. The results of this study provide crucial information regarding the full-length cDNAs that encode the Nile tilapia DnaJ subfamily B member $9 b$ (On-DnaJ B9b) and subfamily $C$ member $3 a(\mathrm{On}$-DnaJ C $3 a)$ genes. The gene organization of these genes was demonstrated. Additionally, we evaluated On-DnaJ B9b and On-DnaJ C3a gene expression levels in Nile tilapia in response to infectious states, especially following S. agalactiae and F. columnare infections, which cause severe issues in Nile tilapia aquaculture worldwide. Biological function analyses of these two genes were performed via gene knockdown techniques. These findings may provide important information at the molecular level for understanding host-pathogen interactions and cellular stress responses in bacteria-infected Nile tilapia. 


\section{Materials and Methods}

\subsection{Experimental Animals}

Juvenile Nile tilapia weighing approximately $30 \mathrm{~g}$ were purchased from a Nile tilapia farm in central Thailand. The fish were acclimatized in a 1000-1 fiberglass tank filled with dechlorinated tap water at the Department of Aquaculture, Faculty of Fisheries, Kasetsart University. The tilapia were fed twice daily with commercial pellet feed. Twenty percent of the water was changed every two days, and feces and waste were removed twice a day. The Nile tilapia were acclimatized under laboratory conditions for 7 days prior to the start of the experiment. The water was continuously aerated using an air stone and oxygen generator.

\subsection{Cloning and Characterization of Nile Tilapia cDNA Encoding the On-DnaJ B9b and On-DnaJ C3a Genes}

The head kidney and spleen of healthy adult Nile tilapia were dissected and stored in TRIzol reagent (Gibco BRL, Waltham, MA, USA) for total RNA extraction. Total RNA was extracted according to the manufacturer's instructions. For the extraction of total RNA, all processes were conducted using a FastPrep ${ }^{\circledR}$ homogenizer (MP Biomedicals, Santa Ana, CA, USA) as recommended by the manufacturer's protocol. Only mRNA was isolated using a QuickPrep Micro mRNA Purification Kit (Amersham Biosciences, Piscataway, NJ, USA) according to the manufacturer's instructions. A $500 \mu \mathrm{g}$ mRNA sample was obtained from each organ, and then, all the samples were pooled together. The ready-to-use 5' and 3' cDNA templates for RACE-PCR were synthesized as recommended by the manufacturer's protocol (Clontech, Fitchburg, WI, USA) by using $1 \mu \mathrm{g} / \mu \mathrm{L}$ of pooled mRNA. Specific primer pairs for On-DnaJ B9b F/On-DnaJ C3a F and On-DnaJ B9b R/On-DnaJ C3a R (Table 1) were generated to conduct $3^{\prime}$ and $5^{\prime}$ RACE-PCR. The specific primers used in this study were designed from a partial EST clone cDNA from a Nile tilapia cDNA library (GenBank accession number FF281612 for On-DnaJ B9b and FF280511 for On-DnaJ C3a), which was used in 5' and $3^{\prime}$ RACE-PCR to recover missing transcript information from both the $5^{\prime}$ and $3^{\prime}$ directions of the On-DnaJ B9b and On-DnaJ C3a cDNAs. The thermal cycler reaction conditions for the $5^{\prime}$ and $3^{\prime}$ RACE-PCR were as follows: 5 cycles of $94{ }^{\circ} \mathrm{C}$ for $30 \mathrm{~s}$ and $72{ }^{\circ} \mathrm{C}$ for $3 \mathrm{~min}$; followed by 5 cycles of $94{ }^{\circ} \mathrm{C}$ for $30 \mathrm{~s}, 70{ }^{\circ} \mathrm{C}$ for $30 \mathrm{~s}, 72{ }^{\circ} \mathrm{C}$ for $3 \mathrm{~min}$; and 25 cycles of $94^{\circ} \mathrm{C}$ for $30 \mathrm{~s}, 68^{\circ} \mathrm{C}$ for $30 \mathrm{~s}$, and $72{ }^{\circ} \mathrm{C}$ for $3 \mathrm{~min}$. The $5^{\prime}$ and $3^{\prime}$ RACE-PCR products were separated by gel electrophoresis using a $1 \%$ agarose gel to determine the amplicon sizes. The products were purified from the gel using a HiYield ${ }^{\mathrm{TM}}$ Gel/PCR DNA fragment extraction kit (RBC Bioscience, New Taipei City, Taiwan).

The purified products were then ligated into the pGEM $^{\circledR}-\mathrm{T}$ Easy vector (Promega, Madison, WI, USA), and the recombinant plasmids were cloned into competent Escherichia coli DH5 alpha cells [30]. The plasmids containing inserts of interest were then sequenced using a Thermo Sequenase fluorescently labeled primer cycle sequencing kit (Amersham Pharmacia Biotech, Piscataway, NJ, USA) with the M13 forward and reverse primers (Macrogen, Inc., Geumcheon-gu, Seoul, Korea).

The homology of the nucleotide sequences was subsequently tested against sequences available in the GenBank database using both the BlastX and BlastN programs (http: / / www.ncbi.nlm.nih.gov / (accessed on 9 March 2021)). The nucleotide sequences of both the $5^{\prime}$ and $3^{\prime}$ directions were aligned with each other, and the joining or overlapping regions were consequently represented in the full-length cDNAs of both the On-DnaJ B9b and OnDnaJ C3a genes. The hydrophobic leader sequence was confirmed using SignalP 3.0 (http: / / www.cbs.dtu.dk/services/SignalP (accessed on 9 March 2021)). The theoretical isoelectric point $(\mathrm{pI})$ and molecular weight of On-DnaJ B9b and On-DnaJ C3a were determined using ExPASy (http:/ / www.expasy.org / (accessed on 9 March 2021)). The similarity and identity of the nucleotide and amino acid sequences of the On-DnaJ B9b and On-DnaJ C3a genes from Nile tilapia and other organisms were computed using the MatGat program, version 2.02 (http:/ / bitincka.com/ledion/matgat (accessed on 9 March 2021)). To predict the threedimensional (3D) structures of On-DnaJB9b and On-DnaJC3a proteins, homology modeling 
was carried out using the SWISS-MODEL database (https: / / www.swissmodel.expasy.org (accessed on 9 March 2021)). The predicted model structures were then visualized with PyMOL software (Schrödinger, Inc., New York, NY, USA).

Table 1. Oligonucleotide primers used.

\begin{tabular}{|c|c|c|c|c|c|}
\hline Gene Name & $\begin{array}{c}\text { Oligonucleotide } \\
\text { Primer }\end{array}$ & $\begin{array}{l}\text { Accession } \\
\text { Number }\end{array}$ & Sequence ( $5^{\prime}$ to $\left.3^{\prime}\right)$ & Amplicon Size & Purpose of Use \\
\hline \multirow{6}{*}{$\begin{array}{l}\text { DnaJ subfamily B } \\
\text { member } 9 b \\
\text { (DnaJB9b) }\end{array}$} & On-DnaJ B9b F & KM_081674 & $\begin{array}{l}\text { GGAGACTACGACTTTAACCAG } \\
\text { CAC }\end{array}$ & 160 & $\begin{array}{l}\text { Real-time PCR, } \\
\text { RACE }\end{array}$ \\
\hline & On-DnaJ B9b R & & $\begin{array}{l}\text { CCTGGAAGTGGCTGTCAAAGT } \\
\text { GTC }\end{array}$ & 160 & $\begin{array}{l}\text { Real-time PCR, } \\
\text { RACE }\end{array}$ \\
\hline & DnaJB9b_F & & GCCGAGAGATGCTACCGAGC & \multirow{2}{*}{225} & \multirow{2}{*}{$\begin{array}{c}\text { Gene } \\
\text { knockdown }\end{array}$} \\
\hline & DnaJB9b_R & & GCCGAGAGATGCTACCGAGC & & \\
\hline & DnaJB9bT7_F & & $\begin{array}{l}\text { GGATCCTAATACGACTCACTA } \\
\text { TAGGGCCGAGAGATGCTACC } \\
\text { GAGC }\end{array}$ & \multirow[t]{2}{*}{250} & \multirow[t]{2}{*}{$\begin{array}{l}\text { Gene } \\
\text { knockdown }\end{array}$} \\
\hline & DnaJB9bT7_R & & $\begin{array}{c}\text { GGATCCTAATACGACTCACTA } \\
\text { TAGGGCCCTCCCCTGATGAA } \\
\text { GCAC }\end{array}$ & & \\
\hline \multirow{6}{*}{$\begin{array}{l}\text { DnaJ subfamily C } \\
\text { member } 3 \\
\text { (DnajC3a) }\end{array}$} & On-DnaJ C3a F & KM_081675 & $\begin{array}{c}\text { CAAGGATTATGTGACAGCTG } \\
\text { CTGC }\end{array}$ & 150 & $\begin{array}{l}\text { Real-time PCR, } \\
\text { RACE }\end{array}$ \\
\hline & On-DnaJ C3a R & & $\begin{array}{l}\text { TGGTGCTCAGCTTGTAGAAA } \\
\text { GCCT }\end{array}$ & 150 & $\begin{array}{l}\text { Real-time PCR, } \\
\text { RACE }\end{array}$ \\
\hline & DnaJC3a_F & & CAGTGGCACCCGGACAACTT & \multirow{2}{*}{225} & \multirow{2}{*}{$\begin{array}{c}\text { Gene } \\
\text { knockdown }\end{array}$} \\
\hline & DnaJC3a_R & & CAGTGGCACCCGGACAACTT & & \\
\hline & DnaJC3aT7_F & & $\begin{array}{c}\text { GGATCCTAATACGACTCACTA } \\
\text { TAGGCAGTGGCACCCGGACA } \\
\text { ACTT }\end{array}$ & \multirow[t]{2}{*}{250} & \multirow[t]{2}{*}{$\begin{array}{c}\text { Gene } \\
\text { knockdown }\end{array}$} \\
\hline & DnaJC3aT7_R & & $\begin{array}{c}\text { GGATCCTAATACGACTCACTA } \\
\text { TAGGCCCGGAGCCAAACGGA } \\
\text { TTGA }\end{array}$ & & \\
\hline \multirow[t]{2}{*}{$\begin{array}{l}\text { Green fluorescence } \\
\text { gene }\end{array}$} & GFP_F & & $\begin{array}{c}\text { TAATACGACTCACTAAGGGA } \\
\text { GACACATGAAGCAGCACGA } \\
\text { CCT }\end{array}$ & & \multirow[t]{2}{*}{$\begin{array}{l}\text { Gene } \\
\text { knockdown }\end{array}$} \\
\hline & GFP_R & & $\begin{array}{c}\text { TAATACGACTCACTATAGGG } \\
\text { AGAAGTTCACCTTGATGCC } \\
\text { GTTC }\end{array}$ & & \\
\hline \multirow[t]{2}{*}{ Beta-actin } & On-Beta-actin F & \multirow[t]{2}{*}{ XM_003443127 } & $\begin{array}{l}\text { ACAGGATGCAGAAGGAGAT } \\
\text { CACAG }\end{array}$ & 155 & Real-time PCR \\
\hline & On-Beta-actin $\mathrm{R}$ & & $\begin{array}{c}\text { GTACTCCTGCTTGCTGATCCA } \\
\text { CAT }\end{array}$ & 155 & Real-time PCR \\
\hline
\end{tabular}

2.3. Gene Organization Structural Analysis of the Nile Tilapia DnaJ B9b and DnaJ C3a Genes

Next, the full-length cDNAs of the Nile tilapia DnaJ B9b and DnaJ C3a genes obtained from the above experiments were blasted against sequence information available in the Ensembl databases (www.ensembl.org (accessed on 29 April 2021)). The exon and intron information for these two genes was evaluated and compared with the DnaJ B9b and DnaJ $C 3 a$ genomic organizations from all other organisms in the available databases.

\subsection{Evolutionary Tree Construction of the DnaJ B9b and DnaJ C3a Genes}

The full-length cDNAs of the Nile tilapia DnaJ B9b and DnaJ C3a genes were excluded from the $5^{\prime}$ and $3^{\prime}$ untranslated region (UTR) sequences to obtain only the open reading frame (ORF) sequences, which were translated to determine the amino acid 
information. The other known DnaJ B9b and DnaJ C3a genes from other vertebrates, including fish, amphibians, birds and mammals, which are available in the GenBank database (http:/ /www.ncbi.nlm.nih.gov/ (accessed on 29 April 2021)), were carefully examined. All sequences were aligned using ClustalW (http:/ / www.clustal.org (accessed on 29 April 2021). A phylogenetic tree was ultimately constructed with the UPGMA method through the MEGA 5.05 program (http: / /www.megasoftware.net (accessed on 29 April 2021)). Bootstrapping with 1000 bootstrap replications was utilized to assess the reliability of the obtained tree. The Nile tilapia HSP70 gene (accession no. ACJ03597), which was evolutionarily distant from these two heat shock proteins, was used as the outgroup.

\subsection{Normal Tissue Distribution of On-DnaJ B9b and On-DnaJ C3a Gene Expression in Healthy Nile Ti-Lapia}

To examine the expression patterns of the On-DnaJ B9b and On-DnaJ C3a genes in various healthy Nile tilapia organs (approximately $30 \mathrm{~g}$ ), we collected thirteen organs: the brain, gills, gonads, heart, anterior kidneys, intestine, liver, muscle, peripheral blood leukocytes (PBLs), skin, spleen, stomach and posterior kidneys. Total RNA was extracted from all tissues using TRIzol reagent, as described in Section 2.2. The quality and quantity of the total RNA were measured using a NanoDrop spectrophotometer (NanoDrop 2000, Thermo Scientific, Waltham, MA, USA). The final concentration was adjusted to $1 \mu \mathrm{g}$ of total RNA, and a RevertAid First Strand cDNA Synthesis Kit (Fermentas, Waltham, MA, USA) was used to synthesize the first-strand cDNA. Real-time RT-PCR was performed in triplicate for each organ using $1 \mu \mathrm{g}$ of first-strand cDNA. For analysis of the On-DnaJ B9b and On-DnaJ C3a mRNA levels in each organ, $4.75 \mu \mathrm{L}$ of distilled water, $6.25 \mu \mathrm{L}$ of Brilliant ${ }^{\circledR}$ II SYBR ${ }^{\circledR}$ Green qPCR Master Mix (Stratagene, La Jolla, CA, USA) and $1 \mu \mathrm{L}$ of $10 \mathrm{mM}$ specific primers for On-DnaJ B9b F/On-DnaJB 9b R and On-DnaJ C3a F/On-DnaJ C3a R (Table 1) were used. Beta-actin gene expression, with specific primers for On-Beta-actin F/On-Beta-actin R (Table 1), was used as a reference gene. The real-time PCR conditions were as follows: an initial denaturation step at $95^{\circ} \mathrm{C}$ for $10 \mathrm{~min}$, followed by 40 cycles of $95^{\circ} \mathrm{C}$ for $30 \mathrm{~s}, 55^{\circ} \mathrm{C}$ for $30 \mathrm{~s}$, and $72{ }^{\circ} \mathrm{C}$ for $1 \mathrm{~min}$, and a final cycle of $95^{\circ} \mathrm{C}$ for $1 \mathrm{~min}$, $55^{\circ} \mathrm{C}$ for $30 \mathrm{~s}$, and $95^{\circ} \mathrm{C}$ for $30 \mathrm{~s}$. The threshold cycle (CT) value was recorded for further calculations used to analyze the expression patterns of the On-DnaJ B9b and On-DnaJ C3a genes in each organ. The relative expression ratios were normalized to the expression levels of each gene in the brain using the $2^{-\Delta \Delta C T}$ method [31].

\subsection{Quantitative Real-Time RT-PCR ( $q$ RT-PCR) Analyses of the On-DnaJ B9b and On-DnaJ C3a} Genes in Response to Systemic Pathogenic Infection

\subsubsection{Preparation of Bacterial Suspension}

The two pathogenic bacteria, S. agalactiae and F. columnare, were isolated from infected fish courtesy of the Laboratory of Aquatic Animal Health Management, Department of Aquaculture, Faculty of Fisheries, Kasetsart University, Thailand. S. agalactiae was enriched in tryptic soy broth (TSB) and incubated at $32{ }^{\circ} \mathrm{C}$ for $18 \mathrm{~h}$. The bacterial cells were centrifuged at $600 \times g$ for $15 \mathrm{~min}$ and washed twice with $0.85 \% \mathrm{NaCl}$. The bacterial suspension concentration was adjusted with a spectrophotometer (Spectronic BioMate 3, Thermo Fisher Scientific, Waltham, MA, USA) at a specific wavelength of $600 \mathrm{~nm}$ with an optical density (OD) of 0.6 , which was equal to $1 \times 10^{9}$ colony forming units per milliliter (CFU/mL). The suspension was diluted 100-fold with normal saline to obtain a bacterial concentration of $1 \times 10^{7} \mathrm{CFU} / \mathrm{mL}$. F. columnare enrichment was also performed, and the cells were cultured in Shieh's broth and incubated at $32{ }^{\circ} \mathrm{C}$ for $18 \mathrm{~h}$. The bacterial cells were precipitated and washed with normal saline as described above. The bacterial concentration $\left(1 \times 10^{9} \mathrm{CFU} / \mathrm{mL}\right)$ was spectrophotometrically adjusted to an OD of 2.1 with a specific wavelength of $525 \mathrm{~nm}$. A $1 \times 10^{7} \mathrm{CFU} / \mathrm{mL}$ bacterial suspension was obtained with the dilution method described above. 


\subsubsection{Experimental Animal Design}

One hundred fifty healthy Nile tilapia (approximately $30 \mathrm{~g}$ weight) were acclimatized for seven days before the start of the experiment. The fish were randomly separated into five groups ( 30 fish each) and reared in experimental blue tanks containing $150 \mathrm{~L}$ of tap water. The rearing water was continuously aerated using air stones and an oxygen generator. During the experimental period, excretion and feces were removed daily, and $20 \%$ of the water was changed every two days. After acclimatization, all fish in group 1 were intraperitoneally injected with $0.1 \mathrm{~mL}$ of normal saline solution $(0.85 \% \mathrm{NaCl})$, which was given as a control treatment. The animals in groups 2 and 3 were intraperitoneally injected with $0.1 \mathrm{~mL}$ of $S$. agalactiae at concentrations of $1 \times 10^{7}$ and $1 \times 10^{9} \mathrm{CFU} / \mathrm{mL}$, respectively. The animals in groups 4 and 5 were injected with $0.1 \mathrm{~mL}$ of $F$. columnare at concentrations of $1 \times 10^{7}$ and $1 \times 10^{9} \mathrm{CFU} / \mathrm{mL}$, respectively, via the same route of administration as the previous groups. After injection, the liver, spleen and head kidney, which are three vital organs that are involved in the immune response, were harvested from three fish in each group and dissected at $6 \mathrm{~h}, 12 \mathrm{~h}, 1$ day, 2 days, 3 days and 7 days after pathogenic administration. These samples were stored in TRIzol for total RNA extraction.

\subsection{3. qRT-PCR Analysis}

Total RNA from each group at the designed time points was extracted and converted to first-stand cDNA following the manufacturer's protocol. One microgram of first-strand cDNA of each organ at different time points was separately used as the target template for qRT-PCR analysis, which was conducted to evaluate the On-DnaJ B9b and On-DnaJ $C 3 a$ gene expression levels with a method similar to that described above. The relative expression ratios of each gene were normalized with $\beta$-actin gene expression levels with the $2^{-\Delta \Delta C T}$ method [31].

\subsection{Silencing Analysis and Effects of On-DnaJ B9b and On-DnaJ C3a Gene Knockdown under Normal Conditions}

\subsubsection{Experimental Design and Double-Stranded RNA (dsRNA) Preparation}

Five hundred Nile tilapia fingerlings (approximately $5 \mathrm{~g}$ ) were acclimatized under laboratory conditions with the methods described above. Fifteen fish each were randomly moved and maintained in 4 different 100-1 glass tanks for seven days. In this study, the water temperature was set at $28 \pm 1.5^{\circ} \mathrm{C}$ using a controlled heating system $\left(\mathrm{HOPAR}^{\mathrm{TM}} \mathrm{K}-339\right.$, Chosion, China). During this time, the gene-specific primers DnaJB9bT7_F/DnaJB9bT7_R and DnaJC3aT7_F/DnaJC3aT7_R (Table 1) were designed to obtain DNA templates containing a T7 promoter. These primers were used to amplify cDNA from Section 2.2 with the same protocol, and the targeted PCR fragments were cloned into the pGEM T-easy vector with the above process. The specific dsRNA sequences for On-DnaJ B9b (dsOnDnaJ B9b) and On-DnaJ C3a (dsOn-DnaJ C3a) and the green fluorescent protein (dsGFP) gene were synthesized using the T7 RiboMAX ${ }^{\mathrm{TM}}$ Express RNAi System (Promega Corporation, Madison, WI, USA) and purified following a previous method described by the manufacturer's protocol.

2.7.2. dsRNA Delivery and qRT-PCR Analysis for Gene Knockdown of the On-DnaJ B9b and On-DnaJ C3a Genes

All fish prepared in 4 tanks in Section 2.7.1. were intraperitoneally injected with different conditions as follows: in the first to fourth tanks, fish were injected with $50 \mu \mathrm{L}$ of phosphate-buffered saline (PBS, pH 7.4), PBS+5 $\mu \mathrm{g}$ dsOn-DnaJ B9b, PBS $+5 \mu \mathrm{g}$ dsOnDnaJ C3a and PBS+5 $\mu$ g dsGFP. After injection, at 6, 12, 24, 48, 72, 96 and $120 \mathrm{~h}$, gill and liver samples of three fish in each group were collected. Total RNA was extracted, and first-strand cDNA synthesis was performed with the methods described above. qRT-PCR analyses of the On-DnaJ B9b and On-DnaJ C3a genes at each time point were conducted with the same protocol described in Section 2.5. 


\subsection{Silencing Analysis and Effects of On-DnaJ B9b and On-DnaJ C3a Gene Knockdown at High} Water Temperature

Fifteen fish each in Section 2.7.1. were randomly moved and maintained in five different $100-1$ glass tanks under stable water temperature at $28 \pm 1.5^{\circ} \mathrm{C}$ with the same method described above for seven days. Prior to dsRNA induction, the water temperature in the second to fifth tanks was gradually increased to $35 \pm 2.1^{\circ} \mathrm{C}$ within $1 \mathrm{~h}$. Then, all fish prepared in five tanks were intraperitoneally injected with different conditions as follows: in the first to fifth tanks, fish were injected with $50 \mu \mathrm{L}$ of PBS (pH 7.4), PBS, PBS+dsGFP, PBS $+5 \mu \mathrm{g}$ dsOn-DnaJ B9b, and PBS $+5 \mu \mathrm{g}$ dsOn-DnaJ C3a. During this period, the behavior and mortality of fish in each group were recorded until day seven.

\subsection{Effects of On-DnaJ B9b and On-DnaJ C3a Gene Silencing under High-Temperature Stress with $S$. agalactiae Infection}

Ten fish each prepared in Section 2.7. were randomly placed in 15 different 100-1 glass tanks for seven days, and then the water temperature of the tanks was raised to $35 \pm 2.1^{\circ} \mathrm{C}$ as described above. Then, every fish in tanks 1-3 and 4-6 was first injected with PBS ( $\mathrm{pH}$ 7.4). The fish in tanks 7-9, 10-12 and 13-15 were intraperitoneally injected with $50 \mu \mathrm{L}$ of PBS $+5 \mu \mathrm{g}$ dsGFP, PBS $+5 \mu \mathrm{g}$ dsOn-DnaJ B9b and PBS $+5 \mu \mathrm{g}$ dsRNA of On-DnaJ C3a, respectively. In the next $2 \mathrm{~h}$, fish in tanks $4-15$ were injected with $50 \mu \mathrm{L}$ of $1 \times 10^{9} \mathrm{CFU} / \mathrm{mL}$ of $S$. agalactiae suspension. After injection, fish in each group were maintained in their tanks. Behavior and mortality were recorded every $6 \mathrm{~h}$ during the first two days and daily until day seven.

\subsection{Statistical Analysis}

The relative expression ratios of the On-DnaJ B9b and On-DnaJ C3a genes in each organ in Section 2.5 and each organ at different time points in each group in Sections 2.6 and 2.7 and accumulative mortality in Sections 2.8 and 2.9. were statistically determined using one-way analysis of variance (ANOVA) followed by Duncan's new multiple range test (DMTR) to evaluate the mean differences in each organ or treatment with $95 \%$ confidence intervals $(p<0.05)$.

\section{Results}

\subsection{Structural Characterization of the Nile Tilapia cDNAs Encoding the On-DnaJ B9b and On-DnaJ C3a Genes}

The total length of the On-DnaJ B9b cDNA was $1951 \mathrm{bp}$, with an $80 \mathrm{bp} 5^{\prime} \mathrm{UTR}$, a $681 \mathrm{bp}$ coding region equal to 227 amino acid residues, and a $1187 \mathrm{bp}$ 3'UTR. Furthermore, a hydrophobic leader sequence was found at amino acid positions 1 to 22 , and three instability motif positions were found in the $3^{\prime} \mathrm{UTR}$ (Figure 1A). The calculated theoretical $\mathrm{pI}$ and molecular weight of On-DnaJ B9b were 6.83 and $26.58 \mathrm{kDa}$, respectively. The multisequence alignment results between DnaJ B9b cDNA of Nile tilapia and other known organisms revealed that this sequence has a signal peptide (22 aa). Additionally, On-DnaJ $B 9 b$ cDNA has a J domain that contains a conserved His-Pro-Asp (HPD) motif, which was predicted to be a BiP-ATPase binding protein (Figure 1B). The g/F region was found downstream of the J domain. No N-linked glycosylation sites (NXS or NXT) were observed throughout the sequence. A ten-amino acid QH-rich insertion was only observed in OnDnaJ B9b. Additionally, the Nile tilapia and zebrafish DnaJ B9b cDNAs had six amino acids that were detected near the C-terminal end (Figure 1B). Based on information from this characterization, the lack of zinc-finger motifs and the organization of the J domain-G/F region-peptide binding fragment pattern, On-DnaJ B9b belongs to type II Hsp40.

The completely characterized full-length cDNA encoding the Nile tilapia DnaJ C3a gene is $1993 \mathrm{bp}$ in total length, with a $58 \mathrm{bp} 5^{\prime} \mathrm{UTR}$, a $1509 \mathrm{bp}$ ORF that corresponds to 503 aa, and a 423 bp 3'UTR (Figure 2A). The calculated pI and molecular weight of On-DnaJ C3a were 7.09 and $57.79 \mathrm{kDa}$, respectively. The multisequence alignments of the Nile tilapia DnaJ C3a cDNA compared with those of other organisms indicated that the On-DnaJ C $3 a$ cDNA contains a 24 aa leader sequence, 9 TPR domains, a J domain with an HPD motif, 
and 2 instability sequences. This organization causes On-DnaJ C3a to cluster into type III Hsp40 (Figure 2B).

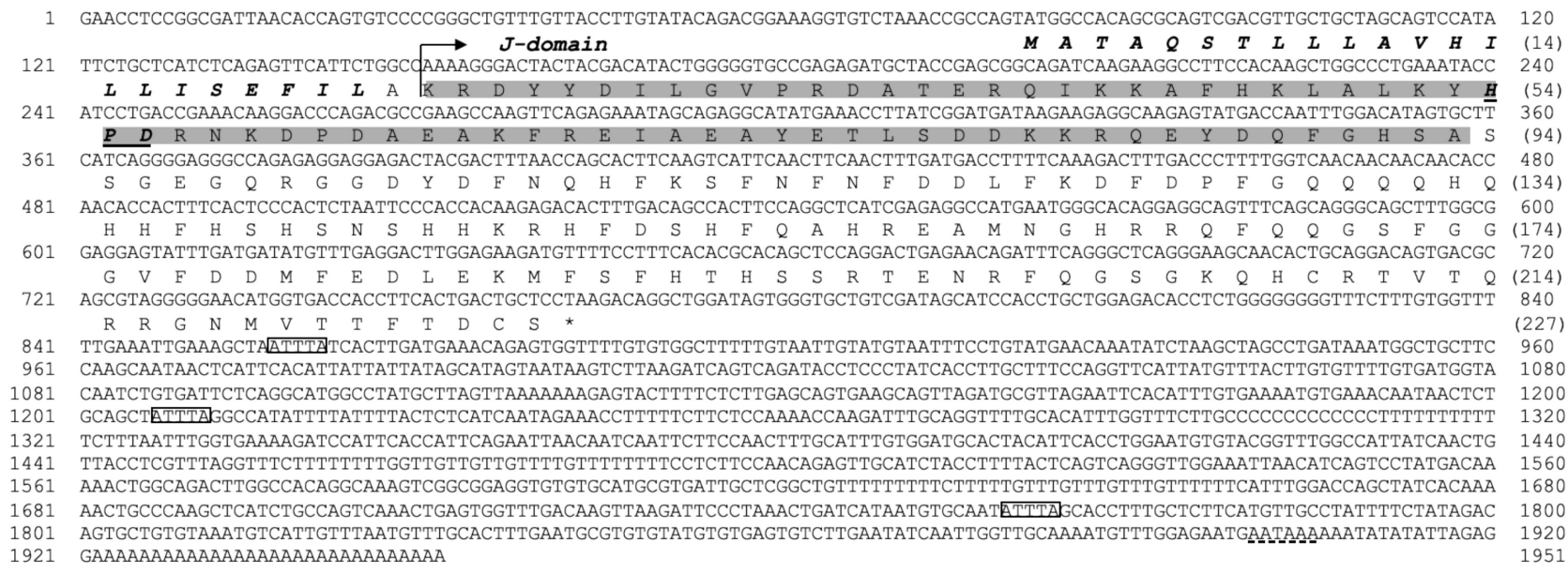

Nile tilapia
Zebrafish
Human
Mouse
Rat
Chicken
Frog


Nile tilapia
Zebrafish
Human
Mouse
Rat
Chicken
Frog

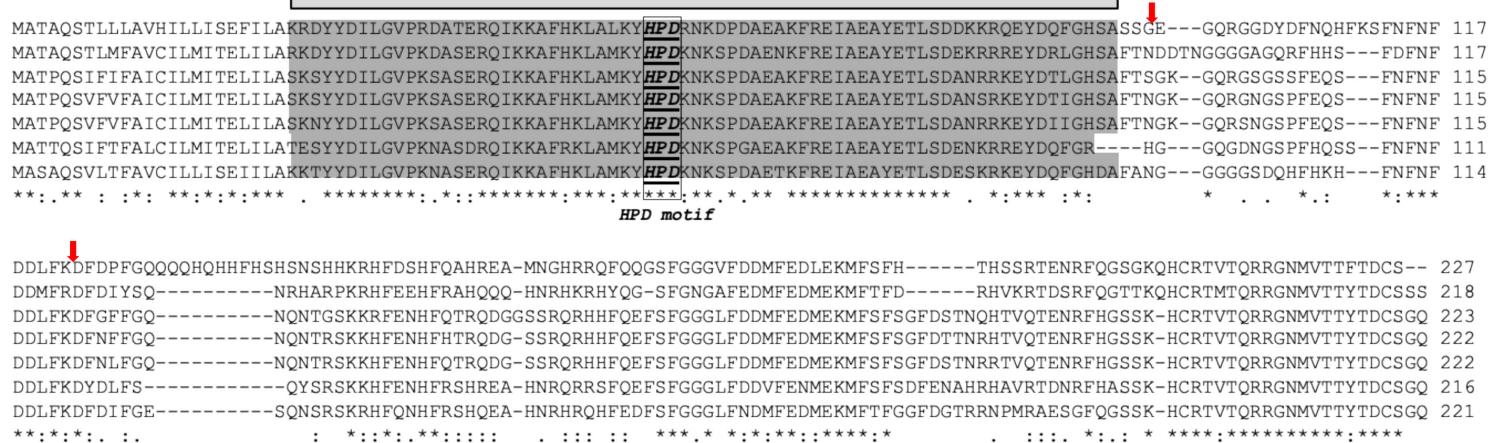

Figure 1. Full-length cDNA encoding the Nile tilapia DnaJ B9b gene (A). The upper and lower lines indicate the nucleotide and amino acid sequences, respectively. The leader sequence is in bold and italics. The J domain is highlighted, and the conserved HPD motif is bolded and underlined. The instability motifs (ATTTA) are shown in boxes. The polyadenylation signal (AATAAA) is underlined with a dashed line. Amino acid sequence alignments of Nile tilapia, zebrafish, human, mouse, rat, chicken and frog DnaJ B9b genes (B). Two red arrows indicate G/F region. The asterisks $\left(^{*}\right)$ indicate conserved residues in all sequences. Colons (:) and dots (.) indicate the high and low conserved residues in most sequences, respectively. The conserved J domain is highlighted in gray. The HPD motif is bolded and underlined in the box.

A comparison of the On-DnaJ B9b gene with other known DnaJ B9b genes from higher vertebrates showed that their nucleotide identity scores were $60.9-64.6 \%$, and their amino acid identity and similarity scores were $60.9-64.7 \%$ and $77.1-81.1 \%$, respectively. The OnDnaJ B9b gene had strong nucleotide identities of $77.7 \%$ and $77.3 \%$ with those of pufferfish and Japanese medaka, respectively, and its amino acid identity scores were $80.9 \%$ and $77.7 \%$, indicating close relationships with pufferfish and Japanese medaka, respectively (Supplemental material Table S1).

A comparison of the On-DnaJ C3a gene with other known DnaJ C3a genes from higher vertebrates showed that their nucleotide identity scores were $66.0-68.0 \%$, and their amino acid identity and similarity scores were $67.5-69.8 \%$ and $82.7-85.9 \%$, respectively. Additionally, the Nile tilapia On-DnaJ C3a gene had $85.2 \%$ and $88.5 \%$ nucleotide and amino acid sequence identities, respectively, and exhibited $95.0 \%$ amino acid similarity with that of Japanese medaka (Supplemental material Table S2).

Homology modeling revealed that On-DnaJB9b exhibited the greatest similarity to DnaJ subfamily B member 9 in humans (PDB 2ctr.1. A), with an identity of $77.46 \%$ (Figure 3A and Supplemental material Figure S1). The conserved His-Pro-Asp (HPD) 
motif of On-DnaJ B9b was found in a random coil region. The On-DnaJC3a model similarly showed that On-DnaJC3a exhibited the highest similarity to DnaJ homolog subfamily C member 3 in humans, the cochaperone P58 (IPK) (PDB 2y4t.3. A), with an identity of $72.37 \%$. The model structure of On-DnaJC3a was found to contain an HPD motif situated next to the loop between the last two alpha-helices (Figure 3B and Supplemental Material Figure S2).


Figure 2. Full-length cDNA encoding the Nile tilapia DnaJ C3a gene (A). The upper and lower lines indicate the nucleotide and amino acid sequences, respectively. The leader sequence is in shown in bold and italics. TPRs no. 1 to 9 are underlined. The J domain is highlighted, and the conserved HPD motif is bolded and underlined. The instability motifs (ATTTA) are shown in boxes. The polyadenylation signal (AATAAA) is underlined with a dashed line. Amino acid sequence alignments of Nile tilapia, salmon, zebrafish, human, mouse, rat, chicken and frog DnaJ C3a genes (B). The asterisks $\left({ }^{*}\right)$ indicate conserved residues in all sequences. Colons (:) and dots (.) indicate high and low conserved residues in most sequences, respectively. The conserved J domain is highlighted in gray. The HPD motif is bolded and underlined in the box. 


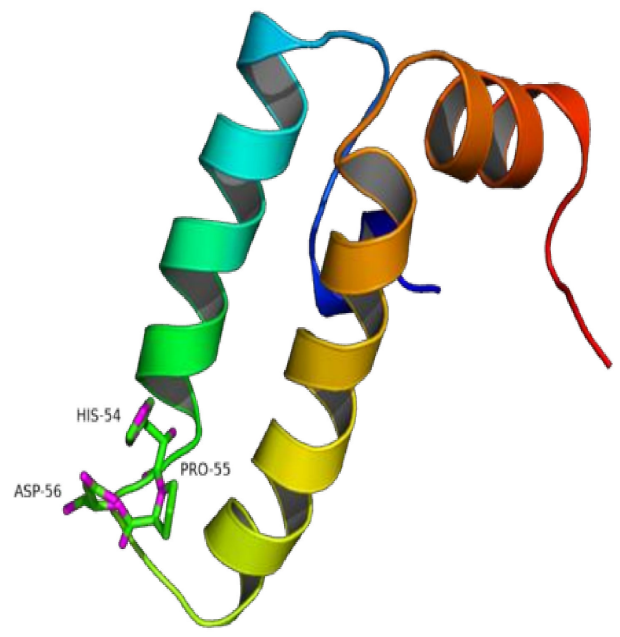

A

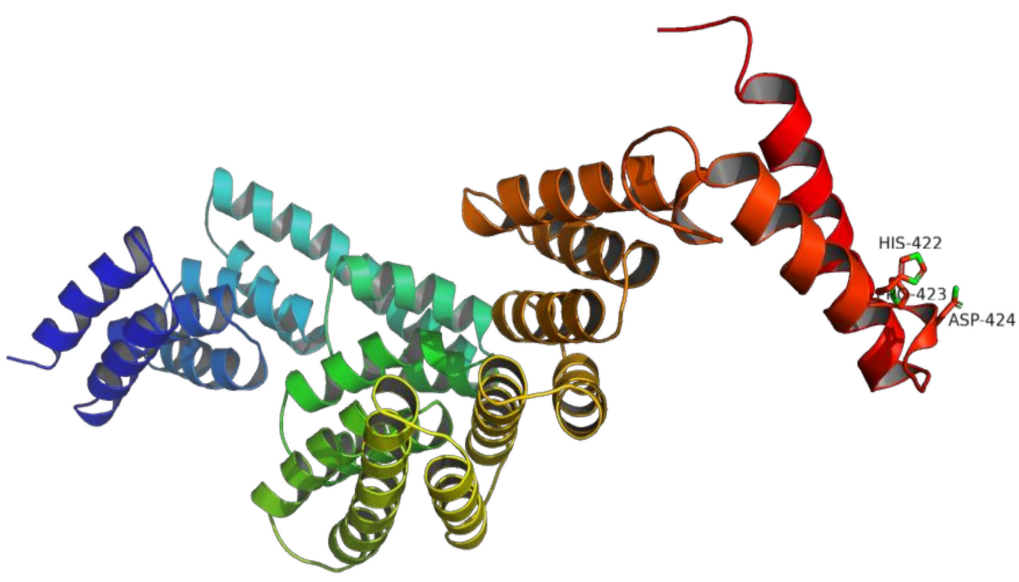

B

Figure 3. Model of the On-DnaJB9b (A) and On-DnaJC3a (B) homology predicted by the SWISS-MODEL program. The HPD motifs are indicated by numbering the amino acid residue. The color of the model is set as a rainbow where the $\mathrm{N}$-terminus is colored blue, the C-terminus is colored red, and residues between 2 termini are rainbow color gradients.

\subsection{Organization of the On-DnaJ B9b and On-DnaJ C3a Genes}

A comparative analysis of the full-length On-DnaJ B9b and On-DnaJ C3a cDNAs and genomic DNA sequences that are available in the Ensembl databases demonstrated that the On-DnaJ B9b gene has a short, fully functional structure that includes $2132 \mathrm{bp}$ organized into two exons and one intron. The first exon (217 bp) contains a 288-bp intron. The last exon (267 bp) is linked to a 1160-bp 3'UTR. The On-DnaJ C3a gene, which comprises $11,988 \mathrm{bp}$, is organized into 12 exons and 11 introns. Its exon lengths are 75-182 bp, while its intron lengths are 96-5257 bp (Figure 4).
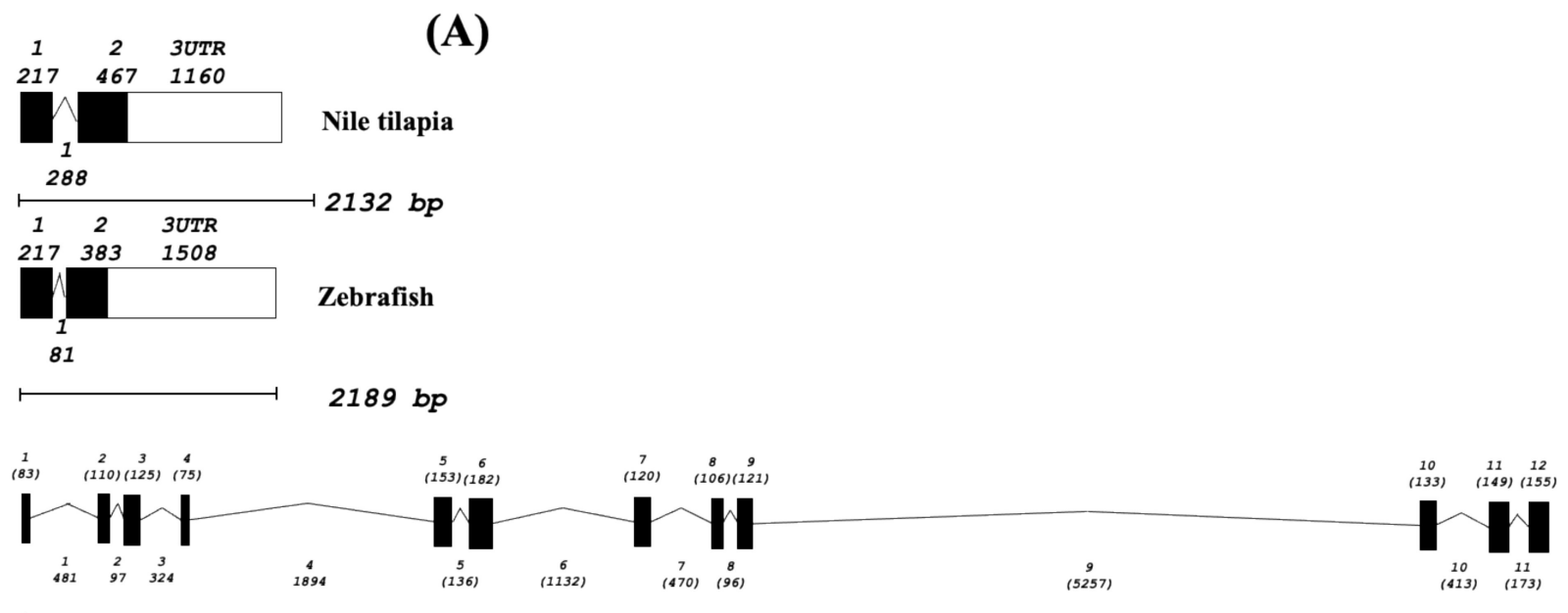

$11988 \mathrm{bp}$

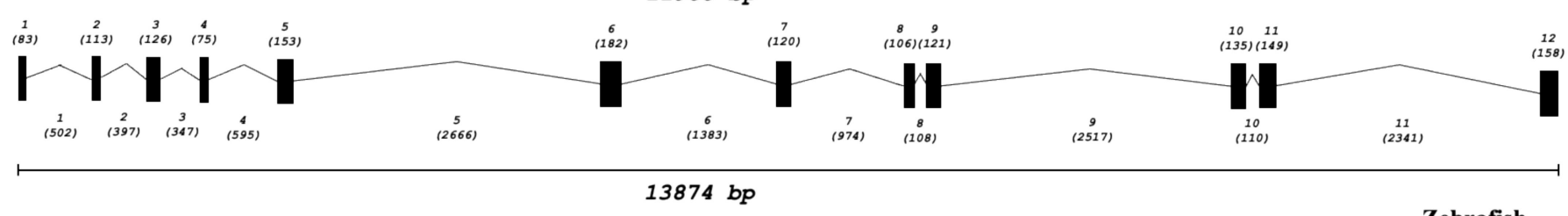

Zebrafish

Figure 4. Genomic organization of the Nile tilapia DnaJ B9b (A) and DnaJ C3a (B) genes. The numbers above each gene structure indicate the exon numbers and their lengths in bp. The numbers below each gene structure indicate the intron numbers and their lengths in bp. 


\subsection{Evolutionary Analysis of the On-DnaJ B9b and On-DnaJ C3a Genes}

The On-DnaJ B9b and On-DnaJ C3a gene phylogenetic trees revealed that these two genes were obviously divided into two individual groups. In each evolutionary clade, the tree was obviously split into two major clusters, which included higher and lower vertebrates. For the DnaJ B9b gene, zebrafish (Danio rerio) DnaJ B9b was grouped into the higher vertebrate branch. The On-DnaJ B9b gene was classified into the Osteichthyes (bony fish) group, which is highly related to pufferfish (Takifugu rubripes) (Class Actinopterygii, Order Tetraodontiformes) and Japanese medaka (Oryzias latipes) (Class Actinopterygii, Order Beloniformes). The On-DnaJ C3a gene was also grouped into the Osteichthyes branch and was closely related to Japanese medaka (Supplemental material Figure S3).

\subsection{On-DnaJ B9b and On-DnaJ C3a Gene Tissue Distribution in Healthy Nile Tilapia}

qRT-PCR analyses of the On-DnaJ B9b and On-DnaJ C3a genes in various healthy Nile tilapia tissues indicated that the $O n-D n a J ~ B 9 b$ transcript was significantly expressed in gonad and trunk kidney tissues and that its expression levels were $5.35 \pm 0.05-$ and $3.15 \pm 0.02$-fold higher than the expression levels in the brain, which was used as a tissue calibrator. In contrast, its expression was $0.08 \pm 0.01$-fold higher in the heart, $0.24 \pm 0.02$-fold higher in the head kidneys and $0.28 \pm 0.01$-fold higher in muscle tissue than in the brain (Figure 5A). On-DnaJ C3a mRNA was highly expressed in the gills ( $5.66 \pm 0.33$-fold), intestine ( $3.42 \pm 0.34$-fold $)$, liver ( $2.08 \pm 0.10$-fold $)$ and trunk kidneys $(2.05 \pm 0.12$-fold $)$; however, its expression was lower in the heart $(0.05 \pm 0.01$-fold $)$ and head kidneys than in the brain (Figure 5B).
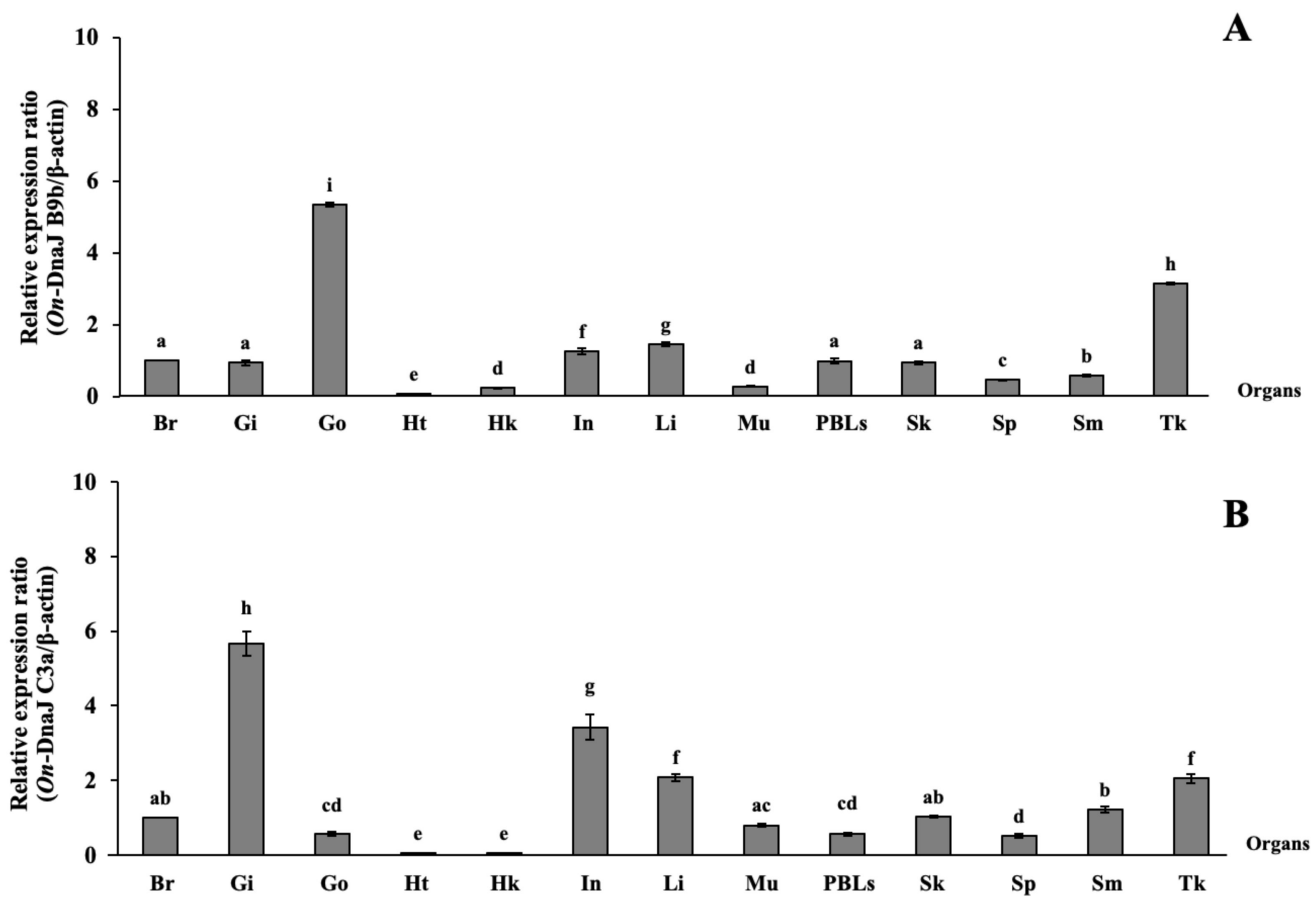

Figure 5. On-DnaJ B9b (A) and DnaJ C3a (B) mRNA expression in normal tissues. Each bar indicates the expression levels in each organ. The different letters above each bar indicate a significant difference. $p<0.05$ was considered significant $(\mathrm{Br}=$ brain, $\mathrm{Gi}=$ gills, $\mathrm{Go}=$ gonad, $\mathrm{Ht}=$ heart, $\mathrm{Hk}=$ head kidney, $\mathrm{In}=$ intestine, $\mathrm{Li}=$ liver, $\mathrm{Mu}=$ muscle, PBLs = peripheral blood leukocytes, $\mathrm{Sk}=$ skin, $\mathrm{Sp}=$ spleen, $\mathrm{Sm}=$ stomach, $\mathrm{Tk}=$ trunk kidney).

3.5. On-DnaJ B9b and On-DnaJ C3a Gene Expression Levels in Nile Tilapia Infected with Two Pathogenic Bacteria

During the experimental periods, there were no deaths of the fish in either bacterial challenge group, but some fish showed significant lethargy in 48-96 h. The results showed that after fish were injected with S. agalactiae, the On-DnaJ B9b transcript levels in the liver 
were significantly upregulated in all treatment groups compared with the control group in a dose-dependent manner, especially at early time points following infection (6-12 h). The highest upregulation of gene expression (117.79 \pm 1.15 -fold) was found in the liver at $12 \mathrm{~h}$ in the $1 \times 10^{9} \mathrm{CFU} / \mathrm{mL}$ S. agalactiae treatment group (Figure $6 \mathrm{~A}$ ). In the spleen, its expression was slightly upregulated at $6 \mathrm{~h}$ only in the $1 \times 10^{9} \mathrm{CFU} / \mathrm{mL}$ group, and it was significantly upregulated $(p<0.05)$ in a dose-dependent manner at $12 \mathrm{~h}(1.91 \pm 0.15$ and $4.67 \pm 0.46$-fold) (Figure 6B). In the head kidneys, gene expression levels were slightly induced at $6 \mathrm{~h}$ in both treated groups and only with $1 \times 10^{9} \mathrm{CFU} / \mathrm{mL}$ treatment; however, the highest expression level was detected at $12 \mathrm{~h}$ (10.71 \pm 0.52 -fold) (Figure $6 \mathrm{C}$ ).

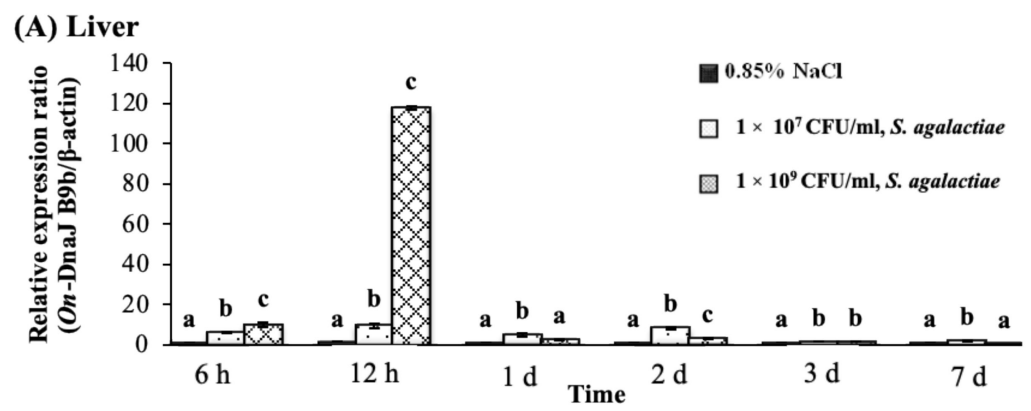

\section{(B) Spleen}

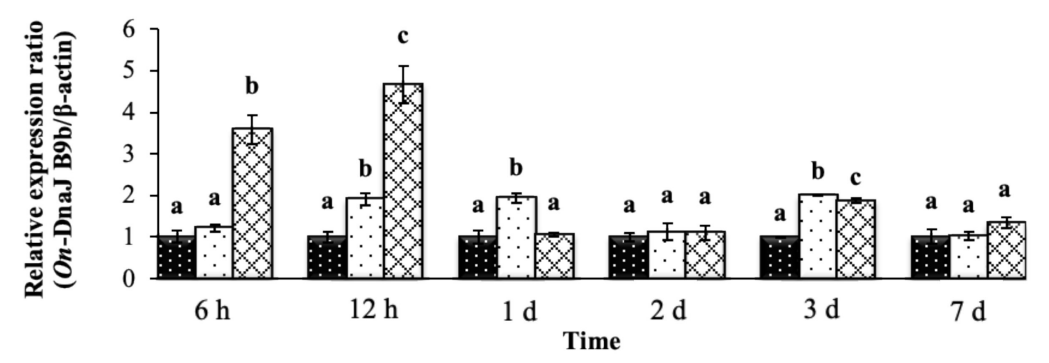

(C) Head kidney

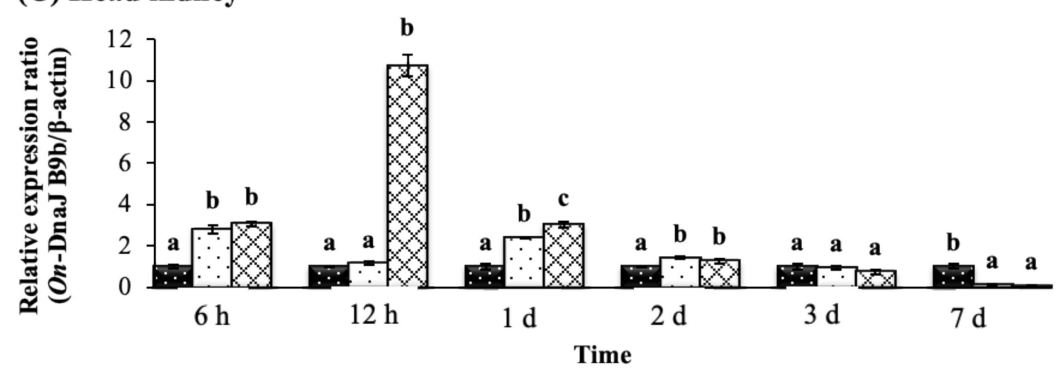

Figure 6. Nile tilapia DnaJ B9b transcript levels in fish exposed to S. agalactiae at $1 \times 10^{7}$ and $1 \times 10^{9} \mathrm{CFU} / \mathrm{mL}$ at different time points in the liver (A), spleen (B) and head kidney (C). The different letters on each bar indicate significant differences $(p<0.05)$. This scheme is also used for Figures 7-11.

In the F. columnare injection groups, On-DnaJ B9b transcriptional levels were found to be highly upregulated in a dose-dependent manner at 6 and $12 \mathrm{~h}$ (Figure $7 \mathrm{~A}, \mathrm{C}$ ). In the liver, the highest On-DnaJ B9b gene expression level showed a 77.20 \pm 3.03 -fold induction at $6 \mathrm{~h}$ in the $1 \times 10^{9} \mathrm{CFU} / \mathrm{mL}$ injection group (Figure 7A). In the spleen, only the $1 \times 10^{9}$ $\mathrm{CFU} / \mathrm{mL}$ treatment showed significantly upregulated expression of On-DnaJ B9b at $6 \mathrm{~h}$, $12 \mathrm{~h}$ and 3 days, and the mRNA levels in all treated groups were dose-dependently induced (Figure $7 \mathrm{~B}$ ). In the head kidneys, transcript levels were significantly upregulated in a dose-dependent manner at 6 and $12 \mathrm{~h}$. However, at 2-7 days, mRNA expression was downregulated at both concentrations (Figure 7C).

The On-DnaJ C3a gene expression levels in fish after S. agalactiae injection with the $1 \times 10^{9} \mathrm{CFU} / \mathrm{mL}$ treatment exhibited the greatest upregulation (51.09 \pm 0.75 -fold) in the liver at $12 \mathrm{~h}$; however, the expression rapidly decreased to $1.60 \pm 0.13$-fold by 
day one (Figure 8A). In the spleen, this mRNA expression was slightly upregulated in a dose-dependent manner at 6 and $12 \mathrm{~h}$, and the highest level was observed at $12 \mathrm{~h}$ ( $3.45 \pm 0.18$-fold induction) in the $1 \times 10^{9} \mathrm{CFU} / \mathrm{mL}$ treatment group (Figure 8B). The On-DnaJ C3a gene showed prolonged expression in the head kidneys until two days after exposure, and a dose-dependent effect was observed at $12 \mathrm{~h}$ and 1 day (Figure $8 \mathrm{C}$ ). The highest expression level (9.13 \pm 0.27 -fold) was found at $12 \mathrm{~h}$ in the $1 \times 10^{9} \mathrm{CFU} / \mathrm{mL}$ treatment group.

In the $F$. columnare injection groups, On-DnaJ C3a mRNA in the liver was highly expressed at 6 and $12 \mathrm{~h}$ (Figure 9a). A dose-dependent expression pattern was only observed at $6 \mathrm{~h}$, with the highest level (27.48 \pm 0.54 -fold) occurring in the $1 \times 10^{9} \mathrm{CFU} / \mathrm{mL}$ treatment group; however, the expression later decreased to $15.51 \pm 0.08$-fold at $12 \mathrm{~h}$ (Figure 9A). In the spleen, a dose-dependent response was only found at $6 \mathrm{~h}$, with the highest level ( $3.75 \pm 0.17$-fold) observed in the group of fish injected with $1 \times 10^{9} \mathrm{CFU} / \mathrm{mL}$ (Figure 9B). In the head kidneys, the On-DnaJ C $3 a$ transcript level was increased in a dosedependent manner from $6 \mathrm{~h}$ through one day (Figure 9C). At two and three days, On-DnaJ $C 3 a$ gene levels were significantly downregulated $(p<0.05)$ in all treatment groups.

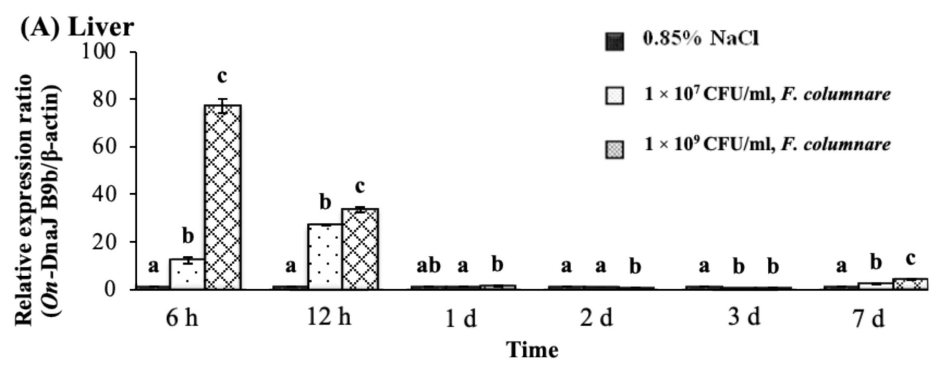

(B) Spleen

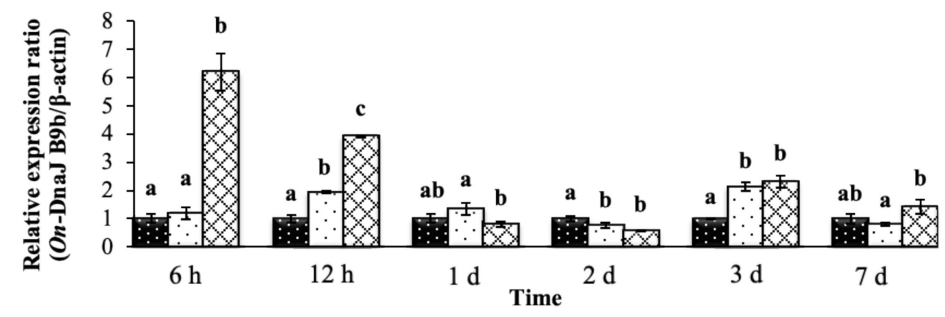

(C) Head kidney

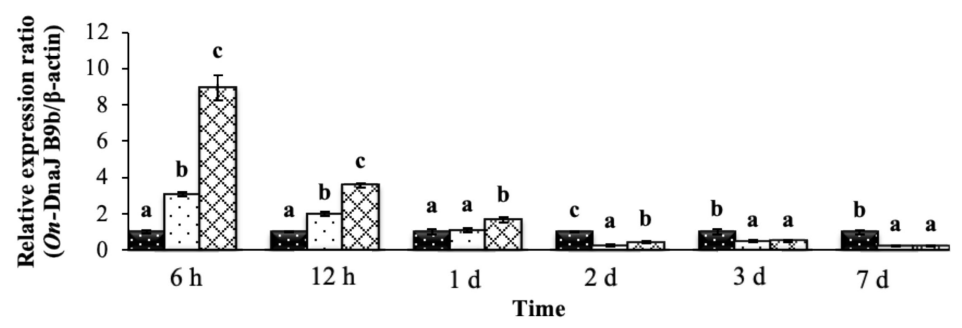

Figure 7. Nile tilapia DnaJ B9b transcript levels in fish exposed to F. columnare at $1 \times 10^{7}$ and $1 \times 10^{9} \mathrm{CFU} / \mathrm{mL}$ at different time points in the liver $(\mathbf{A})$, spleen $(\mathbf{B})$ and head kidneys $(\mathbf{C})$.

\subsection{Gene Silencing Analysis}

On-DnaJ B9b and On-DnaJ C3a expression was obviously knocked down in the target tissues (Figure 10A,C for the gills, Figure 10B,D for the liver). dsOn-DnaJ B9b and dsOnDnaJ C3a strongly induced the degradation of the mRNAs of their target genes. At $12-24 \mathrm{~h}$ after treatment, these two dsRNAs effectively silenced the mRNA expression of the OnDnaJ B9b and On-DnaJ C3a genes. Significantly decreased mRNA levels of these two genes in the RNAi-treated groups were observed from 12 or $24 \mathrm{~h}$ through the end of the experiments at $120 \mathrm{~h}(p<0.05)$ compared to those in the PBS- and dsGFP-injected groups. 


\section{(A) Liver}
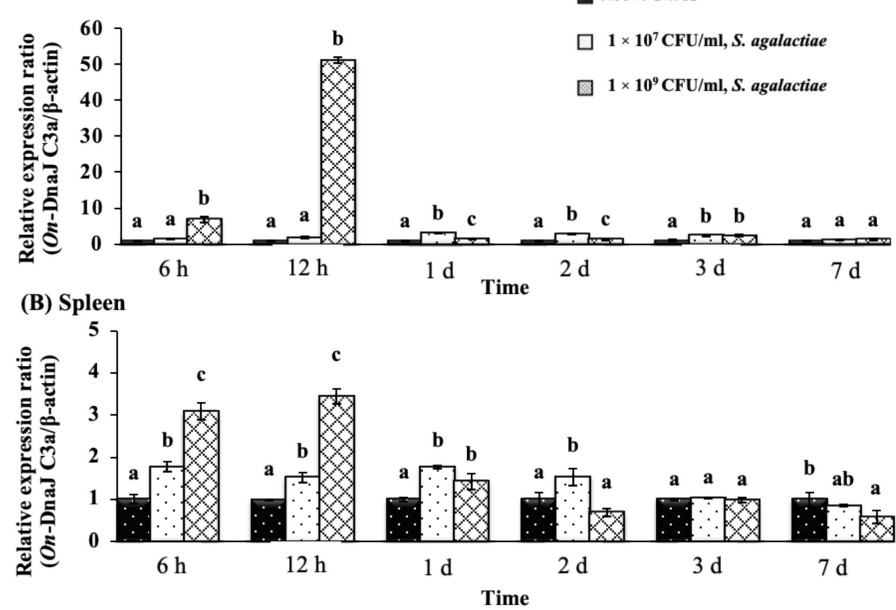

(C) Head kidney

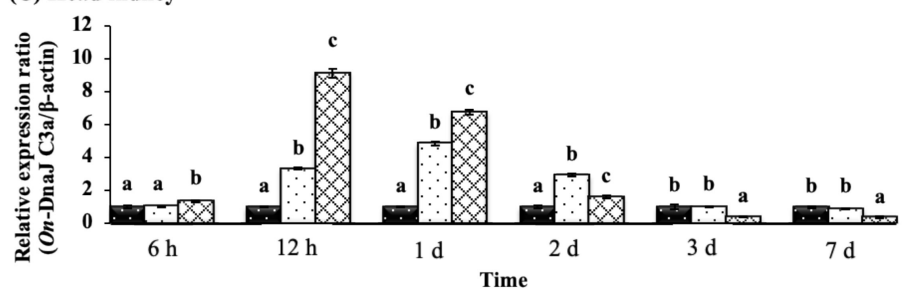

Figure 8. Nile tilapia DnaJ C3a transcript levels in fish exposed to S. agalactiae at $1 \times 10^{7}$ and $1 \times 10^{9} \mathrm{CFU} / \mathrm{mL}$ at different time points in the liver $(\mathbf{A})$, spleen $(\mathbf{B})$ and head kidneys $(\mathbf{C})$.

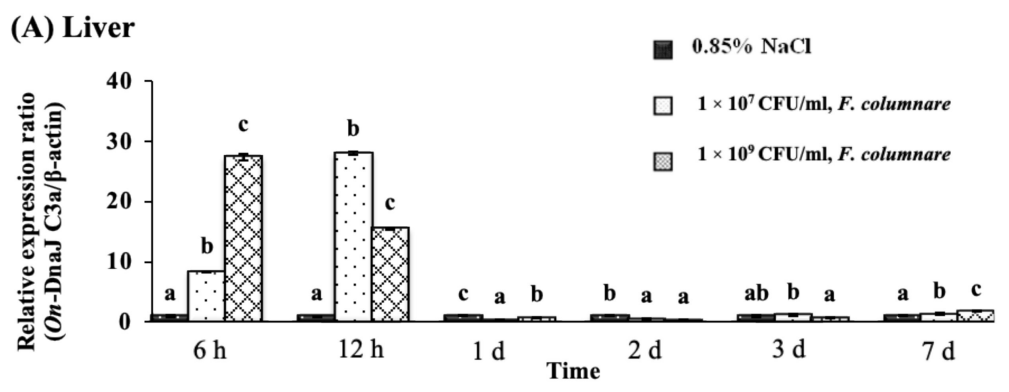

(B) Spleen

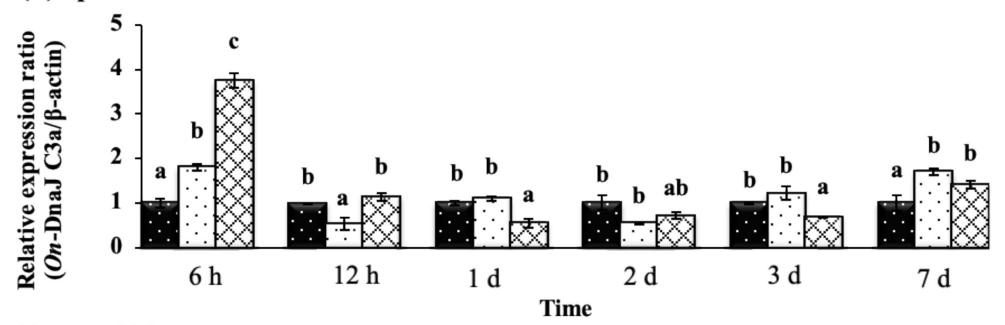

(C) Head kidney

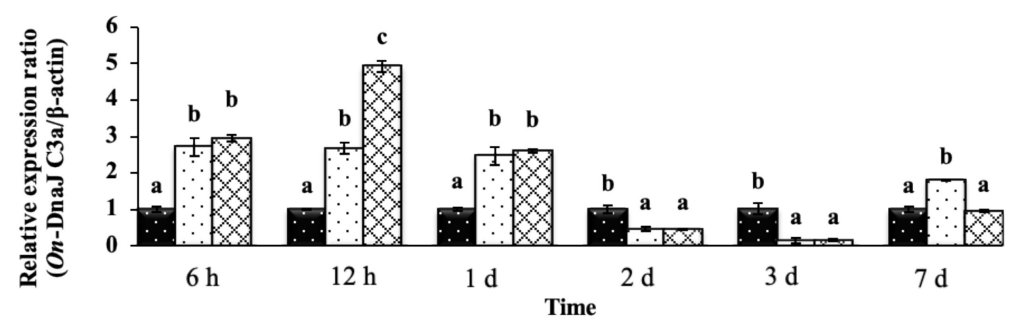

Figure 9. Nile tilapia DnaJ C3a transcript levels in fish exposed to F. columnare at $1 \times 10^{7}$ and $1 \times 10^{9} \mathrm{CFU} / \mathrm{mL}$ at different time points in the liver $(\mathbf{A})$, spleen $(\mathbf{B})$ and head kidneys $(\mathbf{C})$. 
(A)
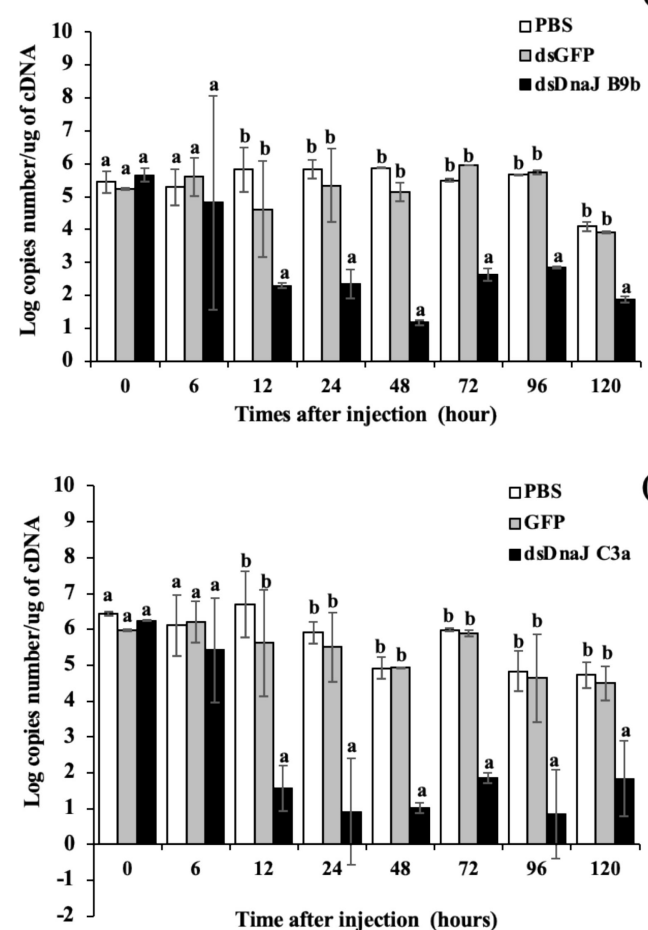

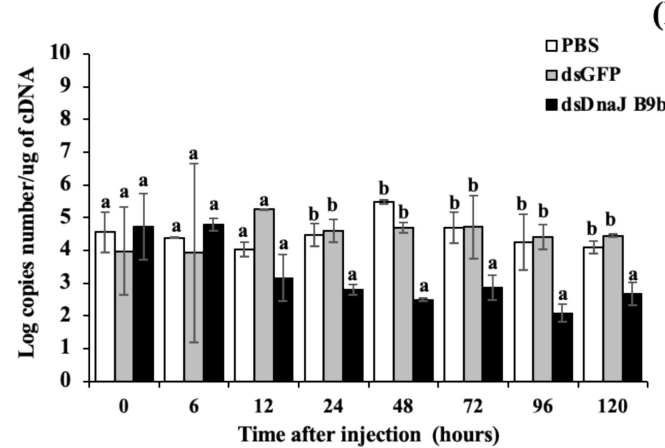

(B)

(C)

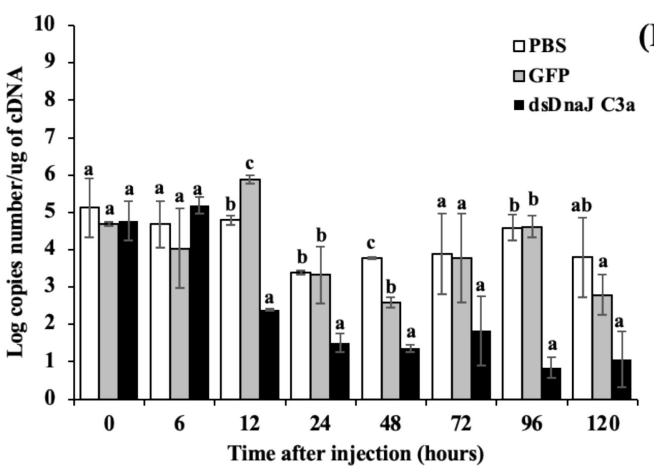

Figure 10. Silencing analysis in the gills $(\mathbf{A}, \mathbf{C})$ and liver $(\mathbf{B}, \mathbf{D})$ of the On-DnaJ B9b and DnaJ C3a genes, respectively, under normal conditions.

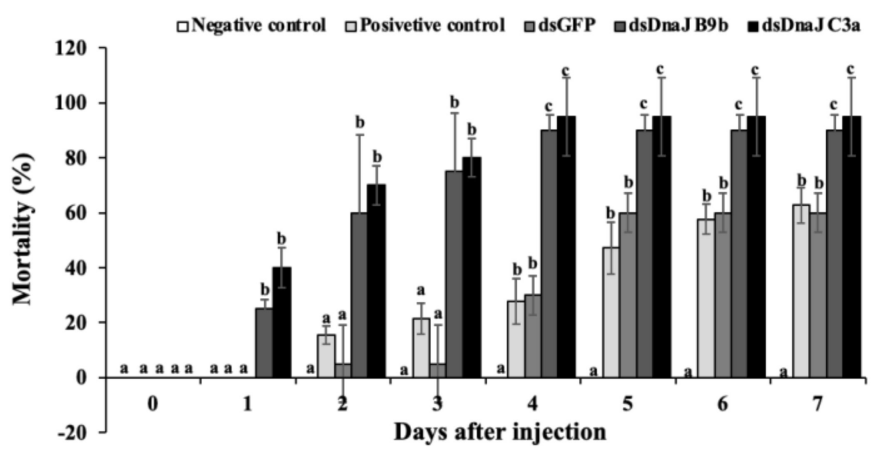

(A)

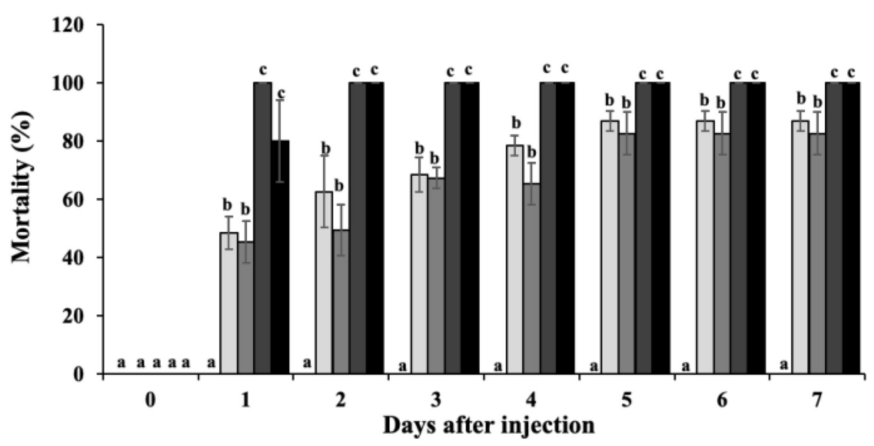

(B)

Figure 11. Effects of On-DnaJ B9b and DnaJ C3a expression knockdown on the mortality of Nile tilapia under high-temperature conditions (A). Negative and positive controls represent the PBS injection group at $28 \pm 1.5^{\circ} \mathrm{C}$ and the PBS injection group at $35 \pm 2.1^{\circ} \mathrm{C}$, respectively. (B) High-temperature and $S$. agalactiae infection conditions; negative and positive controls represent the PBS injection group at $35 \pm 2.1^{\circ} \mathrm{C}$ and PBS-S. agalactaie injection group at $35 \pm 2.1^{\circ} \mathrm{C}$. 


\subsection{Effects of Gene Knockdown under High-Temperature Stress and Coinjection with S. agalactiae}

Under high-temperature conditions, the fish injected with dsOn-DnaJ B9b and dsOnDnaJ C3a initially showed rapid mortality of approximately $25.0 \%$ and $40.0 \%$, respectively, and sunk to the bottom of the containers 1 day after injection. The highest mortality of these groups was observed at days four to seven, and especially at day seven, with mortality rates of $90.0 \%$ and $95.0 \%$; these rates were significantly higher than those of the positive control group, dsGFP-injected group and negative control group, which exhibited mortality rates of $62.7 \%, 60.0 \%$ and $0.0 \%$, respectively (Figure $11 \mathrm{~A}$ ).

High mortality was observed when fish were exposed to both high temperature and S. agalactiae infection (Figure 11B). In this part, the fish coinjected with dsOn-DnaJ B9b and dsOn-DnaJ C3a and S. agalactiae rapidly displayed high mortality at day one after injection, and some fish clearly exhibited erratic or lethargic swimming on the water surface. On day two, these two groups of fish exhibited $100 \%$ mortality with severe hemorrhage on pectoral fins and body surface, while in the positive control (PBS injection group in $35 \pm 2.1^{\circ} \mathrm{C}$ ) and dsGFP-injected groups, which were coinjected with S. agalactiae, some of the fish showed clinical signs similar to previous groups with mortality rates of $62.7 \%$ and $49.5 \%$, respectively. The mortality of these two groups gradually increased and stabilized at $86.8 \%$ and $82.7 \%$ during days five to seven. During this time, no mortality in the negative control group was observed until day 7 (Figure 11B).

\section{Discussion}

In this study, the full-length cDNA encoding the Nile tilapia On-DnaJ B9b gene was cloned and characterized. It was classified as a DnaJ protein type II subfamily member [23] because it is composed of a signal peptide, a J domain, and a glycine $(\mathrm{G})$ / phenylalanine (F)-rich region [32]. The presence of a 22 aa leader sequence suggests that the On-DnaJ B9b protein needs to be translocated to the ER lumen to be further processed. This finding is supported by a previous report [27], in which ERdj4 was identified as a mobile soluble luminal protein found in the ER lumen. A glutamine insertion and a histidine-rich region (130-139 aa) are unique among vertebrates (Figure 1B), suggesting that On-DnaJ B9b may have acquired neofunctionalization. Furthermore, there was a lack of an N-linked glycosylation site (NKS) near the conserved HPD motifs; this site was very highly conserved among the DnaJ B9b molecules. However, On-DnaJ B9b does not have this carbohydratebinding motif at this position or any other regions. This finding suggests that On-DnaJ B9b is not a glycoprotein, and it may have specific functions that are different from previously reported DnaJ B9a molecules from other species. Further study of its function is needed to clarify these important characteristics.

Molecular cloning and structural characterization of On-DnaJ C3a full-length cDNA in Nile tilapia were accomplished. Its cDNA is composed of a 24 aa signal peptide and one J domain, which revealed characteristics of type III Hsp40 [32] with ER-targeted proteins similar to those reported in a previous report [28]. It also has other characteristics of the HSP70 family [33] with multiple functions, such as protein-protein interactions involved in cell cycle regulation, transcription control, protein transport, neurogenesis and protein folding [34-36]. The function of DnaJ C3a is to maintain protein folding homeostasis during the UPR by reducing the misfolded protein burden and promoting protein refolding in the ER lumen via its TPR motif and accompanies BiP as a cochaperone [25,28,29].

3D structure analyses of both the On-DnaJ B9b and On-DnaJ C3a cDNAs revealed conserved HPD motifs in the J domain that are conserved in DnaJ protein families and are important for interactions with other partner molecules [23,33]. Both cDNAs contain 3'UTR instability motifs (ATTTA), and many instability motifs found in the 3'UTR cause the mRNA to be short-lived [37]. This finding suggests a short lifespan of On-DnaJ B9b and On-DnaJ C $3 a$ transcripts in microenvironments in response to ER stress, and these molecules may be rapidly degraded to save host bioenergy. A homology analysis between On-DnaJ B9b and On-DnaJ C3a (Supplemental material Tables S1 and S2) indicated that only the J domains were conserved between the cDNAs with relatively low amino acid identity and similarity. 
These data suggest that these DnaJ proteins have experienced evolutionary differences even though they are in the same family, as indicated by evolutionary tree analysis.

Finally, the evolutionary trees of both genes show high conservation among vertebrates, indicating similar fundamental functions in biological systems. These results suggested that DnaJ B9b (ERdj4) was more highly conserved in vertebrates than in invertebrates, and no homologs were found in Caenorhabditis elegans, yeast, or Drosophila melanogaster databases, as shown in a previous study [23].

A qRT-PCR analysis of On-DnaJ B9b gene expression in healthy Nile tilapia revealed high expression in the gonad and trunk kidney tissues. In the gonads, the new protein synthesis and/or misfolded protein overload rates may be higher than those in other tissues. Additionally, the weights of the experimental Nile tilapia used in this study were only approximately $30 \mathrm{~g}$ (premature stage); therefore, it is possible that the reproductive system in the gonad tissues is still continuously developing at this stage. Previously, it was found that Mdg1 (DnaJ B9b or ERdj4) transcripts were more highly expressed in rat (Rattus norvegicus) testes than in other normal tissues and were significantly induced in rat mesangial cells that were exposed to methanol [22]. This finding suggests that the DnaJ $\mathrm{B} 9 \mathrm{~b}$ protein may play a vital role in translational regulation, especially in the gonads and kidneys. Additionally, DnaJ B9b (ERdj4) transcripts were highly expressed in the liver, placenta, and kidneys of humans [23]. Information from these studies suggested that these tissues contained well-developed intracellular ERs that produce many secreted proteins.

The highest expression of On-DnaJ C3a was observed in the gills, followed by the intestine, liver and trunk kidneys of normal Nile tilapia. It is likely that all these tissues have a high risk of exposure to numerous stressors, leading to increased misfolded/unfolded protein burdens that can overload cells, especially in the ER compartment [34]. Therefore, cells maintain cellular homeostasis by activating protein refolding, in which the On-DnaJ C3a protein and other ER chaperones contribute to a lower number of unfolded proteins. It was suggested that DnaJ C3a (P58 $8^{\mathrm{IPK}}$ ) is universally expressed in all tissues and plays a role in multiple stress responses, according to observations glucosuria, hyperglycemia and increased apoptosis in pancreatic islet cells from mutant mice with a P58 ${ }^{\mathrm{IPK}}$ deletion [33]. It was previously demonstrated that P58IPK - / - mice had excessive ER stress, increased apoptotic signals and exacerbated colitis. This finding suggests a critical function of DnaJ C3a in cytoprotection under cellular stress conditions [38].

In Nile tilapia, F. columnare and S. agalactiae were classified as severe pathogens that kill fish in slightly different manners. F. columnare can preferentially infect under conditions of rapidly fluctuating water quality, such as temperature and water hardness [39], while S. agalactiae is severely virulent at high water temperatures $\left(>31^{\circ} \mathrm{C}\right)[3,40]$

We examined the expression patterns of the On-DnaJ B9b and On-DnaJ C3a genes in response to $S$. agalactiae and F. columnare, one of which is a Gram-positive bacterium and the other is a Gram-negative bacterium. On-DnaJ B9b transcript levels in the liver, spleen and head kidneys were significantly upregulated at 6 and $12 \mathrm{~h}$ and were slightly changed at one to seven days. These patterns were not different from those in different pathogenic infections, suggesting that fish can modulate misfolded/unfolded proteins by inducing the On-DnaJ B9b protein to activate misfolded protein degradation via the ERAD mechanism, which has been clearly demonstrated in mammalian cells [25-27]. Similar to the On-DnaJ B9b mRNA response, the On-DnaJ C3a transcripts in the liver, spleen and head kidneys were substantially induced in the early phase of infection within 1 day. This finding suggests that the fish body attempts to reduce misfolded protein burdens in the ER lumen by increasing On-DnaJ C3a protein levels. The basic function of On-DnaJ C3a in the UPR response has been well documented $[25,28,38]$.

Acute phase proteins (APPs) are strongly produced in fish early following infection $[41,42]$. APPs are mainly synthesized in the fish liver upon the induction of cytokines and inflammatory mediators (IL-1, IL-6, and TNF- $\alpha$ ) that are secreted into the plasma [4143]. Based on this information, the liver is an important organ during the early phase following infection. Experimentally, the most substantial changes in On-DnaJ B9b and 
On-DnaJ C3a gene expression levels in the liver suggested that a fundamental function of hepatocytes is to inductively produce APPs with the help of various chaperone HSPs during synthesis and posttranslational processes. Furthermore, both pathogenic bacteria highly altered the expression levels of the On-DnaJ B9b and On-DnaJ C $3 a$ transcripts early after injection. These results suggested that these fish may use a variety of components in their innate immune responses to eliminate invasion during the early stage of infection. Additionally, in comparison among the tested organs, the livers of the infected fish showed strongly upregulated expression compared with the spleen and head kidney. This suggests that during an infectious state, the fish liver is the major organ maintaining bodily homeostasis by producing many APPs and other antimicrobial substances against bacterial invasion [41,42].

Recently, it was shown that hemolysin toxins, including streptolysin O (SLO) and streptolysin S (SLS), which are produced by group A Streptococcus (GAS), can induce host ER stress and UPR [44]. In our study, a group B Streptococcus (GBS) member S. agalactiae that induces $\beta$-hemolytic effects [45] could clearly cause major changes in On-DnaJ B9b and On-DnaJ C3a expression levels in the livers of the infected fish. These results suggest that GBS also induces ER stress and the UPR in fish. Additionally, F. columnare was found to highly upregulate the expression of these genes in the liver, suggesting that gram-negative bacteria have the potential to induce ER stress and the UPR in the host. It was also found that ER stress could be induced in lipopolysaccharide (LPS)-treated mice by increasing certain transcription factors (ATF4, X-box binding protein 1 [XBP1] and CCAAT-enhancerbinding protein [C/EBP] transcription factor [CHOP]) [46]. All of these factors are involved in cellular stress and apoptotic processes, which lead to acute lung injury in LPS-treated mice. This phenomenon suggests that these transcription factors, which are found in higher vertebrates following LPS-mediated induction, could also be involved in fish infected with Gram-negative F. columnare.

Generally, the host uses protein recognition receptors (PRRs) and APCs to respond to bacterial invasion via recognition of pathogen-associated molecular patterns (PAMPs) [47,48]. PAMP-PRR complexes can activate major intracellular signaling changes in host cells, resulting in a rapid induction in the expression of genes involved in inflammatory and immune responses $[47,48]$. These results suggested that Nile tilapia utilize PRRs to recognize S. agalactiae and F. columnare to trigger immunological responses. HSPs provide chaperoned polypeptides via MHC class II in APCs for specific triggering of the acquired immune response [48], suggesting that On-DnaJ B9b and On-DnaJ C3a are involved in antigenic processing in APCs during the infection period.

In fish, expression analyses of Hsp 40s have been intensively conducted in very few species. It was shown that the expression of 42 of 57 Hsp 40 in the gills, liver and intestine of channel catfish (Ictalurus punctatus) was strongly regulated in response to Edwardseilla ictaluri and F. columnare, especially in early infectious stages [49], suggesting their involvement in disease defenses in fish. The regulatory layer of these proteins, which governs the functional specificities of Dnaj cochaperones and their interactions with HSP70s, could be key to the wide range of cellular functions in the defense mechanisms of fish [50]. Upregulation of Dnaj expression after exposure to bacterial pathogens may strongly drive the interaction binding of heat shock factors (HSFs) and heat shock elements (HSEs) in HSP gene clusters to eventually produce the target heat shock proteins responding to those infectious diseases [51].

To date, information on the characterization and functional analyses of the DnaJ B9b and DnaJ C3a genes in fish is very limited. In the present study, functional analyses by RNAi techniques were first described in Nile tilapia. The dsOn-DnaJ B9b- and dsOn-DnaJ C3ainjected groups showed higher mortality (90-95\%) than the control groups and induced very severe mortality of the tested fish $(100 \%)$ within one to two days under S. agalactiae and heat coinduction. These results strongly demonstrate the crucial functional roles of these two proteins in both heat stress and pathogenic bacterial infection. The absence of these crucial proteins may seriously affect the UPR in the ER lumen [21]. Without ER 
DnaJs in UPR induction conditions, regulation and maintenance of the proper folding of impaired proteins in the lumen may not occur [23]. The lack of On-DnaJ B9b and On-DnaJ C3a might induce dysfunction of the ERAD pathway or prevent normal proteasomal degradation [25-27] or fail to maintain protein folding homeostasis and protein refolding in the ER lumen under UPR conditions $[25,29]$. These effects strongly induce susceptibility to both high-temperature stress and S. agalactiae infection in Nile tilapia.

\section{Conclusions}

This is the first report demonstrating the molecular cloning, gene organization and structural characterization of cDNAs encoding two novel ER chaperone genes in Nile tilapia. This information is crucially important for evolutionary research on DnaJ molecules. We also obtained valuable information regarding host-pathogen interactions by investigating host ER chaperone gene expression changes in both gram-positive and gram-negative bacterial invasion. The ER acts as a protein factory as well as a site for posttranscriptional modification and signals to other molecules that are involved in protein folding in response to ER stress; as shown in this study, the ER contains ER chaperones that mediate immune system responses to systemic pathogenic infections.

Supplementary Materials: The following are available online at https:/ /www.mdpi.com/article/10 $.3390 /$ biom11101509/s1, Table S1. Homology analysis of the nucleotide and amino acid sequences of the On-DnaJ B9b gene. Table S2. Homology analysis of the nucleotide and amino acid sequences of the On-DnaJ C3a gene. Figure S1. Homology model of On-DnaJB9b. (A) Comparison with a nonredundant set of PDB structures of the On-DnaJB9b model and (B) local quality plot. Figure S2. Model of On-DnaJC3a homology. (A) Comparison with a nonredundant set of PDB structures of the On-DnaJC3a model and (B) local quality plot. Figure S3. Phylogenetic trees of the Nile tilapia DnaJ $B 9 b$ and DnaJ C3a genes.

Author Contributions: Conceptualization, P.S.; methodology, P.S.; software, K.T. and P.S.; validation, K.T. and P.S.; formal analysis, K.T., R.W. and P.S.; investigation, K.T., R.W. and P.S.; resources, P.S.; data curation, K.T. and P.S.; writing-original draft preparation, K.T. and P.S.; writing-review and editing, K.T. and P.S.; visualization, P.S.; supervision, P.S.; project administration, P.S.; funding acquisition, P.S. All authors have read and agreed to the published version of the manuscript.

Funding: This work was supported by Thailand Science Research and Innovation (TSRI) (RDG6220035).

Institutional Review Board Statement: This study was carried out in accordance with the principle of the Basel Declaration and the recommendations of the Guide for the Care and Use of Laboratory Animals of the Ethical Committee of Kasetsart University, Thailand, with the approval number ACKU63-FIS-006 (approval date 10 August 2020).

Informed Consent Statement: Not applicable.

Acknowledgments: This work was supported by the Human Resource Development in Science Project (Science Achievement Scholarship of Thailand, SAST); the Office of the Higher Education Commission (OHEC); and the Ministry of Education, Thailand and Kasetsart University Research and Development Institute (KURDI), Kasetsart University, Thailand.

Conflicts of Interest: The authors declare no conflict of interest.

\section{References}

1. Valentin, F.N.; Nascimento, N.F.; Silva, R.C.; Tsuji, E.A.; Paes, M.C.F.; Koberstein, T.C.R.D.; Nakaghi, L.S.O. Maternal age influ-ences on reproductive rates in Nile tilapia (Oreochromis niloticus). R. Bras. Zootec. 2015, 44, 161-163. [CrossRef]

2. Pretto-Giordano, L.G.; Müller, E.E.; De Freitas, J.C.; Da Silva, V.G. Evaluation on the Pathogenesis of Streptococcus agalactiae in Nile Tilapia (Oreochromis niloticus). Braz. Arch. Biol. Technol. 2010, 53, 87-92. [CrossRef]

3. Amal, M.N.A.; Zamri-Saad, M. Streptococcosis in tilapia (Oreochromis niloticus): A review. Pertanika J. Trop. Agric. Sci. 2011, 34, 195-206.

4. Mian, G.; Godoy, D.; Leal, C.; Yuhara, T.; Costa, G.; Figueiredo, H. Aspects of the natural history and virulence of S. agalactiae infection in Nile tilapia. Vet. Microbiol. 2009, 136, 180-183. [CrossRef]

5. Rodkhum, C.; Kayansamruaj, P.; Pirarat, N. Effect of water temperature on susceptibility to Streptococcus agalactiae sero-type Ia infection in Nile tilapia (Oreochromis niloticus). Thai J. Vet. Med. 2011, 41, 309-314. 
6. Durborow, R.M.; Thune, R.L.; Hawke, J.P.; Camus, A.C. Columnaris disease a bacterial infection caused by Flavobacterium columnare. SRAC 1998, 479, 1-4.

7. Decostere, A.; Haesebrouck, F.; A Devriese, L. Shieh medium supplemented with tobramycin for selective isolation of Flavobacterium columnare (Flexibacter columnaris) from diseased fish. J. Clin. Microbiol. 1997, 35, 322-324. [CrossRef]

8. Zhu, W.; Yang, G.; Zhang, Y.; Yuan, J.; An, L. Generation of Biotechnology-Derived Flavobacterium columnare Ghosts by PhiX174 GeneE-Mediated Inactivation and the Potential as Vaccine Candidates against Infection in Grass Carp. J. Biomed. Biotechnol. 2012, 2012, 760730. [CrossRef]

9. Pilarski, F.; Rossini, A.J.; Ceccarelli, P.S. Isolation and characterization of Flavobacterium columnare (Bernardet et al. 2002) from four tropical fish species in Brazil. Braz. J. Biol. 2008, 68, 409-414. [CrossRef]

10. Robert, J. Evolution of heat shock protein and immunity. Dev. Comp. Immunol. 2003, 27, 449-464. [CrossRef]

11. Roberts, R.J.; Agius, C.; Saliba, C.; Bossier, P.; Sung, Y.Y. Heat shock proteins (chaperones) in fish and shellfish and their potential role in relation to fish health: A review. J. Fish Dis. 2010, 33, 789-801. [CrossRef]

12. Ryckaert, J.; Pasmans, F.; Tobback, E.; Duchateau, L.; Decostere, A.; Haesebrouck, F.; Sorgeloos, P.; Bossier, P. Heat shock proteins protect platyfish (Xiphophorus maculatus) from Yersinia ruckeri induced mortality. Fish Shellfish. Immunol. 2010, 28, $228-231$. [CrossRef] [PubMed]

13. Cha, I.S.; Kwon, J.; Bin Park, S.; Bin Jang, H.; Nho, S.W.; Kim, Y.K.; Hikima, J.-I.; Aoki, T.; Jung, T.S. Heat shock protein profiles on the protein and gene expression levels in olive flounder kidney infected with Streptococcus parauberis. Fish Shellfish. Immunol. 2013, 34, 1455-1462. [CrossRef]

14. Ding, Z.; Wu, J.; Su, L.; Zhou, F.; Zhao, X.; Deng, W.; Zhang, J.; Liu, S.; Wang, W.; Liu, H. Expression of heat shock protein 90 genes during early devel-opment and infection in Megalobrama amblycephala and evidence for adaptive evolution in teleost. Dev. Comp. Immunol. 2013, 41, 683-693. [CrossRef] [PubMed]

15. Feder, M.E.; Hofmann, G.E. Heat-shock proteins, molecular chaperones, and the stress response: Evolutionary and eco-logical physiology. Annu. Rev. Physiol. 1999, 61, 243-282. [CrossRef]

16. Iwama, G.K.; Thomas, P.T.; Forsyth, R.B.; Vijayan, M.M. Heat shock protein expression in fish. Rev. Fish Biol. Fish. 1998, 8, 35-56. [CrossRef]

17. Udono, H. Heat shock protein magic in antigen trafficking within dendritic cells: Implications in antigen cross-presentation in immunity. Acta Med. Okayama 2012, 66, 1-6.

18. Roy, C.R. Exploitation of the endoplasmic reticulum by bacterial pathogens. Trends Microbiol. 2002, 10, 418-424. [CrossRef]

19. Zhao, L.; Ackerman, S.L. Endoplasmic reticulum stress in health and disease. Curr. Opin. Cell Biol. 2006, 18, 444-452. [CrossRef]

20. Komura, T.; Sakai, Y.; Honda, M.; Takamura, T.; Wada, T.; Kaneko, S. ER stress induced impaired TLR signaling and mac-rophage differentiation of human monocytes. Cell Immunol. 2013, 282, 44-52. [CrossRef]

21. Martinon, F. The endoplasmic reticulum: A sensor of cellular stress that modulates immune responses. Microbes Infect. 2012, 14, 1293-1300. [CrossRef]

22. Prols, F.; Mayer, M.P.; Renner, O.; Czarnecki, P.G.; Ast, M.; Gassler, C.; Wilting, J.; Kurz, H.; Christ, B. Upregulation of the cochaperone Mdg1 in en-dothelial cells is induced by stress and during in vitro angiogenesis. Exp. Cell Res. 2001, $269,42-53$. [CrossRef]

23. Shen, Y.; Meunier, L.; Hendershot, L.M. Identification and Characterization of a Novel Endoplasmic Reticulum (ER) DnaJ Homologue, Which Stimulates ATPase Activity of BiP in Vitro and Is Induced by ER Stress. J. Biol. Chem. 2002, 277, 15947-15956. [CrossRef]

24. Lee, A.S. The ER chaperone and signaling regulator GRP78/BiP as a monitor of endoplasmic reticulum stress. Methods 2005, 35, 373-381. [CrossRef]

25. Otero, J.H.; Lizák, B.; Hendershot, L.M. Life and death of a BiP substrate. Semin. Cell Dev. Biol. 2010, 21, 472-478. [CrossRef]

26. Kaufman, R.J.; Back, S.H.; Song, B.; Han, J.; Hassler, J. The unfolded protein response is required to maintain the integrity of the ER, prevent oxidative stress, and preserve differentiation in $\beta$-cells. Diabetes Obes. Metab. 2010, 12, 99-107. [CrossRef] [PubMed]

27. Lai, C.W.; Otero, J.H.; Hendershot, L.M.; Snapp, E. ERdj4 protein is a soluble endoplasmic reticulum (ER) DnaJ family pro-tein that interacts with ER-associated degradation machinery. J. Biol. Chem. 2012, 287, 7969-7978. [CrossRef] [PubMed]

28. Tao, J.; Petrova, K.; Ron, D.; Sha, B. Crystal Structure of P58(IPK) TPR Fragment Reveals the Mechanism for its Molecular Chaperone Activity in UPR. J. Mol. Biol. 2010, 397, 1307-1315. [CrossRef] [PubMed]

29. Petrova, K.; Oyadomari, S.; Hendershot, L.M.; Ron, D. Regulated association of misfolded endoplasmic reticulum lumenal proteins with P58/DnaJ C3a. EMBO J. 2008, 27, 2862-2872. [CrossRef]

30. Sambrook, J.; Russel, D.W. Molecular Cloning: A Laboratory Manual; Cold Spring Harbour Laboratory Press: Cold Spring Harbour, NY, USA, 2001; Volumes 1-3.

31. Livak, K.J.; Schmittgen, T.D. Analysis of relative gene expression data using real-time quantitative PCR and the 2- $\Delta \Delta C T$ method. Methods 2001, 25, 402-408. [CrossRef] [PubMed]

32. Qian, X.; Sha, B. Heat Shock Protein 40: Structural Studies and Their Functional Implications. Protein Pept. Lett. 2009, 16, 606-612. [CrossRef]

33. Qiu, X.-B.; Shao, Y.-M.; Miao, S.; Wang, L. The diversity of the DnaJ/Hsp40 family, the crucial partners for Hsp70 chaperones. Cell. Mol. Life Sci. 2006, 63, 2560-2570. [CrossRef] [PubMed] 
34. Korth, M.J.; Lyons, C.N.; Wambach, M.; Katze, M.G. Cloning, expression, and cellular localization of the oncogenic 58-kDa inhibitor of the RNA-activated human and mouse protein kinase. Gene 1996, 170, 181-188. [CrossRef]

35. Melville, M.W.; Katze, M.G.; Tan, S.-L. P58IPK, a novel cochaperone containing tetratricopeptide repeats and a J-domain with oncogenic potential. Cell. Mol. Life Sci. 2000, 57, 311-322. [CrossRef]

36. D'Andrea, L.D.; Regan, L. TPR proteins: The versatile helix. TIBS 2003, 28, 655-662. [CrossRef]

37. Savant-Bhonsale, S.; Cleveland, D. Evidence for instability of mRNAs containing AUUUA motifs mediated through translationdependent assembly of a $>20$ S degradation complex. Genes Dev. 1992, 6, 1927-1939. [CrossRef]

38. Declercq, A.M.; Haesebrouck, F.; Broeck, W.V.D.; Bossier, P.; Decostere, A. Columnaris disease in fish: A review with emphasis on bacterium-host interactions. Vet. Res. 2013, 44, 27. [CrossRef]

39. Mishra, A.; Nam, G.H.; Gim, J.A.; Lee, H.E.; Jo, A.; Kim, H.S. Current challenges of Streptococcus infection and effective mo-lecular, cellular, and environmental control methods in aquaculture. Mol. Cells 2018, 41, 495-505. [PubMed]

40. Cao, S.S.; Zimmermann, E.M.; Chuang, B.; Song, B.; Nwokoye, A.; Wilkinson, J.E.; Eaton, K.A.; Kaufman, R.J. The Unfolded Protein Response and Chemical Chaperones Reduce Protein Misfolding and Colitis in Mice. Gastroenterology 2013, 144, 989-1000. [CrossRef]

41. Tort, L.; Balasch, J.C.; Mackenzie, S. Fish immune system. A crossroads between innate and adaptive responses. Inmunología 2003, 22, 277-286.

42. Bode, J.G.; Albrecht, U.; Häussinger, D.; Heinrich, P.C.; Schaper, F. Hepatic acute phase proteins-Regulation by IL-6- and IL-1-type cytokines involving STAT3 and its crosstalk with NF-kB-dependent signaling. Eur. J. Cell. Biol. 2012, 91, 496-505. [CrossRef]

43. Kovacevic, N.; Hagen, M.O.; Xie, J.; Belosevic, M. The analysis of the acute phase response during the course of Trypanoso-ma carassii infection in the goldfish (Carassius auratus L.). Dev. Comp. Immunol. 2015, 53, 112-122. [CrossRef] [PubMed]

44. Baruch, M.; Hertzog, B.B.; Ravins, M.; Anand, A.; Youting, C.C.; Biswas, D.; Tirosh, B.; Ehanski, E. Induction of endoplasmic reticulum stress and unfolded protein response constitutes a pathogenic strategy of group A streptococcus. Front. Cell. Infect. Microbiol. 2014, 4, 105. [CrossRef]

45. Liu, G.; Zhang, W.; Lu, C. Comparative genomics analysis of Streptococcus agalactiae reveals that isolates from cultured ti-lapia in China are closely related to the human strain A909. BMC Genom. 2013, 14, 775. [CrossRef] [PubMed]

46. Endo, M.; Oyadomari, S.; Suga, M.; Mori, M.; Gotoh, T. The ER Stress Pathway Involving CHOP Is Activated in the Lungs of LPS-Treated Mice. J. Biochem. 2005, 138, 501-507. [CrossRef]

47. Akira, S.; Uematsu, S.; Takeuchi, O. Pathogen recognition and innate immunity. Cell 2006, 124, 783-801. [CrossRef] [PubMed]

48. Colaco, C.A.; Bailey, C.R.; Walker, K.B.; Keeble, J. Heat Shock Proteins: Stimulators of Innate and Acquired Immunity. BioMed Res. Int. 2013, 2013, 461230. [CrossRef]

49. Song, L.; Zhang, J.; Li, C.; Yao, J.; Jiang, C.; Li, Y.; Liu, S.; Liu, Z. Genome-wide identification of Hsp40 genes in channel cat-fish and their regulated expression after bacterial infection. PLoS ONE 2014, 9, e115752. [CrossRef]

50. Faust, O.; Abayev-Avraham, M.; Wentink, A.S.; Maurer, M.; Nillegoda, N.; London, N.; Bukau, B.; Rosenzweig, R. HSP40 proteins use class-specific regulation to drive HSP70 functional diversity nature research. Nature 2020, 587, 1-6. [CrossRef]

51. Benarroch, E.E. Heat shock proteins: Multiple neuroprotective functions and implications for neurologic disease. Neurology 2011, 76, 660-667. [CrossRef] 